\title{
Evaluating solar energy technical and economic potential on rooftops in an urban setting: the city of Lethbridge, Canada
}

\author{
Fariborz Mansouri Kouhestani ${ }^{1}\left[\right.$ - James Byrne ${ }^{1} \cdot$ Dan Johnson $^{1} \cdot$ Locke Spencer $^{1} \cdot$ Paul Hazendonk $^{1}$. \\ Bryson Brown ${ }^{1}$
}

Received: 11 June 2018 / Accepted: 30 October 2018 / Published online: 9 November 2018

(c) The Author(s) 2018

\begin{abstract}
Solar energy deployment is gaining greater attention as a sustainable source of energy that could alleviate aspects of the current climate crisis. Knowledge of the characteristics and economics of the solar electricity sector is required to integrate it in the energy generation and utilization mix. Unlike energy generation from fossil fuels, renewable energy sources have relatively low geographic density and are spread unevenly over large areas. Therefore, especially in cities, where space has greater value and opportunity costs, finding suitable spaces for implementing solar systems are essential to promote the use of solar technologies. Using remote-sensing data, the intricate topography of cities can be modelled, and insolation incident at each location can be estimated. A multi-criteria approach based on geographic information systems (GIS) and light detection and ranging (LiDAR) is used in this research to estimate rooftop photovoltaic electricity potential of buildings in an urban environment, the city of Lethbridge. An economic assessment is conducted utilizing present market prices to determine economically attractive rooftop PV systems. The total rooftop photovoltaic (PV) electricity potential is evaluated and compared with the local electricity demand. Effective expansion of solar power systems in the city is achieved by determining the geographic distribution of the best locations for exploiting the systems. This study estimates that the rooftop PV electricity generation potential of the city of Lethbridge is approximately $301 \pm 29$ (SD) GWh annually (almost $38 \%$ of its annual electricity consumption in 2016), and about $96 \%$ of the recognized potential rooftop PV systems are economically feasible. The results can assist in making informed policy decisions about investment in deployment of renewable energy generation.
\end{abstract}

Keywords GIS $\cdot$ LiDAR $\cdot$ NPV $\cdot$ Rooftop photovoltaic potential $\cdot$ Suitable rooftop areas $\cdot$ Economic assessment

\section{Introduction}

Extensive energy generation and consumption are the main anthropogenic sources of greenhouse gas emissions and air pollution (two-thirds of all human-induced GHG emissions) [1]. Unless sufficient countermeasures are taken in the energy sector, the progressive deterioration of the environment related to these emissions will continue [1]. The rapid and growing global movement towards low-carbon energy sources in response to the imperative of addressing global warming may support a global sustainable energy future and alleviation of some environmental burdens [1]. By introducing new sources of natural capital and exploiting

Fariborz Mansouri Kouhestani

mansouri@uleth.ca

1 University of Lethbridge, 4401 University Drive W, Lethbridge, AB T1K 6T5, Canada replenishing resources, renewables play a crucial role in efforts to de-carbonise energy supplies and avert negative impacts associated with climate change [2]. Renewable energy system uses diverse sources, localises energy generation, decreases transport costs, and reduces long-term price variability [2]. Renewables are now well recognized as the main stream of energy worldwide and supplied $19.3 \%$ of the global final energy usage in 2015 [3]. Increasing development of solar PV is mostly due to improving competitiveness and cost parity with other technologies, new government plans, increasing awareness of the potentials of this technology, and rising electricity demand [3]. Substantial increases in rooftop solar PV installation resulted in buildings becoming the largest available urban source of space for deployment [4]. In fact, globally, about half of the PVs presently installed capacity is composed of distributed PV systems [5]. However, a large capacity is still untapped [5]. 
To supply the increasing needs of energy while avoiding climate change and maintaining quality of life, cities require rigorous and holistic sustainable action plans [4]. Cities currently accommodate more than $50 \%$ of the global population and are an important contributor to global warming, accounting for $65 \%$ of global energy demand and $70 \%$ of human-induced (energy-related) $\mathrm{CO}_{2}$ emissions [4]. Immense renewable energy sources have the largest potential to improve the sustainability of the urban environment, and PV has demonstrated the most potential to contribute in the energy mix, among available micro-generation technologies $[4,6]$. The number of cities worldwide that have decided to move towards $100 \%$ renewable energy and carbon neutrality targets has increased [4]. Some cities have implemented promising policy measures to motivate distributed clean energy development, including rules that oblige utility companies to buy renewable power and building codes that compel the installation of renewable technologies [4]. Some cities and local authorities plan to create a livable, sustainable, and resilient space for their inhabitants [3]. However, in general, cities are not well-equipped to cope with many urban growth and sustainability challenges [7].

Onsite rooftop PV energy micro-generation could decrease the electricity distribution and transmission costs and losses [8]. The lack of investors' and home-owners' awareness about rooftop PV potential, and the detailed information deficit regarding rooftop spaces suitable for PV installation are important barriers that have impeded the diffusion of rooftop PV systems [5, 9]. Significant research on city-wide distributed renewable energy generators is required to attain a sustainable urban energy mix [7]. This research focuses on the technical and economic potential of the roof-mounted photovoltaic (PV) systems in large areas. Estimation of PV potential is challenging, but indispensable for relevant renewable energy policy making [5]. The evaluation of the adequate available roof surfaces is the most crucial stage in implementation of roof-integrated PV applications [10]. Utilizing light detection and ranging (LiDAR) data, geographic information system (GIS) methods, and $\mathrm{PV}$-performance modeling, the proposed method is an efficient and scalable technique which can be automated and replicated effectively. A new detailed method for calculating solar resource availability using ArcGIS was employed [11]. Solar analyst required inputs which were calculated for the region and the accuracy of the simulated radiation was examined by comparing the results with measured data. Moreover, measured meteorological data were used to define a slope factor that was applied to ArcGIS-simulated global radiation estimates on horizontal surfaces. In addition, the economic potential of rooftop PV systems has been investigated. Considering all building types in the city boundary including commercial and industrial buildings is one of the strengths of the applied methodology. In addition to the quantification of the potential amount of electricity generation, the results reveal which percentage of roof areas is economically viable for PV deployment. The findings can provide an established reference point for rooftop PV in the region and be used by energy and building sectors, and policy makers to assess new development opportunities and guide investments towards clean energy technologies [10]. To our knowledge, a rigorous comprehensive assessment of rooftop PV technical potential and economic attractiveness in our study region has not been previously published.

\section{Background}

Technical potential quantifies the maximum possible energy production utilizing a specific renewable energy technology in a particular location or region [8]. Rooftops are the best situated parts of buildings to harvest solar energy and generate electricity [12]. Calculating the rooftop solar potential is not always simple [12]. Rooftop PV potential in urban environments has been estimated in the various regions across globe [13]. Depending on the size of the study region, the type of available data, and the expected results, different methods of estimation have been used [6]. These methods try to assess essential elements such as solar incident intensity, usable roof area availability, and shadows cast by nearby objects [6]. Some studies establish a relationship between population density, building densities, and roof areas, especially for large regions [6]. The outputs of studies like these are not usually applicable at individual and local scales [6]. Based on a representative sample of buildings, Ordóňez et al. used statistical construction data and digital urban maps to measure the useful roof surface area of the sample, and extrapolated the characterization of the sample to the total study region to estimate the solar energy potential in Andalusia (Spain) [13]. Izquierdo et al. calculated the roof area available for solar applications based on land use, population, and building density data using a representative sample of GIS maps of urban areas [10]. They assessed irradiation potential by employing hourly meteorological data from weather stations using Erbs model and Liu-Jordan isotropic model [10]. Establishing a relationship between per capita suitable rooftop area and population density by linear regression on solar rooftop potential data from 1600 cities, IEA (International Energy Agency) Energy Technology Perspectives report derived the rooftop solar PV power capacity in other cities [14]. Sometimes, the inclination angle of different rooftop surfaces and the spatio-temporal variation of insolation are ignored. The IEA value may be used as a starting point in evaluating PV-generation potential, but follow-up evaluation is required.

There are three essential methods for identifying the suitable roof surfaces for PV installation in urban settings: 
constant-value methods, manual selection methods, and GIS-based methods [8]. Constant-value methods assume that a certain fraction of total roof area is usable for placing PV panels [8]. Presenting several methods for creating rooftop PV supply curves, Denholm and Margolis translated the total roof area into usable area using an availability factor [15]. They estimated that residential and commercial buildings in their study site have roof area availability factors of $22-27 \%$ and $60-65 \%$, respectively [15]. The availability factor of roof area takes into account obstructions and shading from other parts of the roof or neighboring features [15]. Constant-value method is simple and not computationally intensive, because it does not take into account the complexity of rooftops and surrounding objects such as tree canopies [8]. Manual selection method utilizes sources such as aerial photography and Google Earth to assess the suitability of roof planes of buildings individually [8]. Although manual selection can precisely determine the total suitable rooftop area, it is time-consuming and cannot be easily applied to large sites [8]. Anderson et al. used an IMBY (In My Backyard) solar simulation tool which allows users to draw polygons to estimate the total rooftop area within a city [16].

GIS-based methods are the most practical and effective techniques for the estimation of usable rooftop area $[8,17]$. These methods are more precise than constant-value methods and can be applied to much larger data sets compared with a manual selection approach [8]. Martin et al. reviewed different procedures for the solar potential assessment in urban areas [18]. Singh and Banerjee used land use data and GIS-based satellite image analysis for estimating the building footprint area and the rooftop PV potential for the Indian city of Mumbai [19]. They employed the Liu-Jordan model to calculate the plane-of-array irradiation and determined the optimum PV tilt angle for the study site and inferred that up to $20 \%$ of the average daily electricity demand of the city can be met by rooftop PV [19]. Jakubiec and Reinhart presented a method for estimating city-wide electricity gains from PV panels by creating 3D urban models using LiDAR data and ArcGIS, Daysim-based hourly radiation simulations, and hourly calculated rooftop temperatures [20]. Creating a 3D urban model is crucial when assessing PV rooftop potential in an urban environment [18]. A precise knowledge of the PV potential requires a comprehensive study of the spatial dimensions of the site [18]. The emergence of LiDAR technology has provided a great opportunity for dense urban area mapping [21].

Methods using DEMs (Digital Elevation Model) employ rooftop irradiation or the number of annual daylight hours in determining proper roof areas [20]. The DEMs are often generated from LiDAR data, and are the most accurate source for measuring the details of an entire urban area [20]. Gagnon et al. used LiDAR data, geographic information system (GIS) methods, and PV-generation modeling to estimate the suitable rooftops for installing PV in 128 cities in the United States [8]. Then, they estimated the PV potential of the entire continental United States employing the results from analysis of areas covered by LiDAR data [8]. Jochem et al. used LiDAR point clouds and a region-growing process to detect potential roof points and perform solar potential analysis for each point [22]. They considered the shadow cast by adjacent objects and the effects of cloud cover by calculating the horizon of each point within the point cloud and employing data from a nearby ground weather station, respectively [22]. Using a GIS-based method and utilizing LiDAR data, Gooding et al. ranked seven major UK cities according to their capacity to generate electricity from roof-mounted PV systems [6]. They calculated a solar city indicator taking into account the socio-economic factors such as income, education, environmental consciousness, building stock, and ownership [6]. The results revealed that the local buildings' characteristics affect the physical and socio-economic rooftop PV potential of a city significantly and indicated areas that require policy attention to promote maximum PV use [6].

Different procedures for analyzing solar potential in urban environments have various drawbacks, and the existing rooftop PV evaluations inferred from the methods may be imprecise $[5,20]$. In some methods, the shading caused by urban context such as trees and neighboring buildings is not considered, or differentiation among the orientations and slopes of roof segments are not conducted [20]. Many studies require assumptions about the orientation and slope of rooftops [23]. Furthermore, few solar potential estimation methods suppose that all rooftops are flat and a constant portion of them is suitable for PV installation [20]. Rooftop PV studies rarely investigate the economic potential of these systems [24]. In this study, a new detailed method for calculating solar resource availability using ArcGIS was employed. In addition, the economic potential of rooftop PV systems was investigated.

\section{Methods}

Modeling the built area, the insolation incident assessment, and the estimation of the suitable roof area is essential in evaluating a building's potential in solar rooftop PV energy generation [25]. Urban area modeling is an active research field in Geography [25]. Urban areas are dense environments composed of diverse artificial and natural features. This complexity makes building rooftops attractive for solar PV installation [26]. Building rooftops provide a large expanse of generally unused area for PV energy production [8]. In the urban context, the existence of various artificial and natural objects including buildings and trees influences the sunlight regime considerably [21]. Accordingly, an accurate solar 
insolation simulation model that considers the complexity of the urban form is required to identify relevant aspects of the urban energy landscape [21]. In an urban environment, representations of three-dimensional form such as elevation, surface slope and aspect, and surrounding obstructing objects determine the accuracy of such simulations [27]. Roof surfaces with different slopes and orientations, reflection, and shadings from the neighboring objects were modelled separately.

\section{Study area}

This study was conducted in Alberta, Canada. Solar electricity can become a mainstream and reliable energy source in Canada and revolutionize its energy mix [28]. The premium quality renewable resources of Alberta could allow this province to become a leader in solar, wind, and bioenergy [29]. Notwithstanding this potential, much of the province's renewable resources are untapped [29]. The city of Lethbridge $\left(49.7^{\circ} \mathrm{N}, 112.8^{\circ} \mathrm{W}\right)$ is in southern Alberta, Canada, a region that receives relatively high rates and extensive hours of solar radiation, with an annual mean daily global horizontal radiation of $3.77 \mathrm{kWh} / \mathrm{m}^{2}$ and $2506 \mathrm{~h}$ of bright sunlight (Fig. 1) [30,31]. With a moderate continental climate, Lethbridge is characterized by warm summers and mild winters, and has more than 320 days of sunshine per year, which is relatively high among Canadian cities [31]. This city has a total land area of $124.3 \mathrm{~km}^{2}$ with a large and growing volume of residential and commercial buildings, which justifies new steps towards building a self-sustainable urban setting [31]. To our knowledge, an extensive evaluation of rooftop photovoltaic solar potential has not yet been undertaken in this city. Low-height and horizontally dispersed buildings over a large area most likely provide a significant rooftop PV electricity potential. The total number of residential, government, medical, educational, commercial, industrial, and cultural buildings in Lethbridge is 55,877 (January 2017) (Table 1) [32]. This city had a total population of 96,828 in 2016 [33].

\section{Data}

The size of the study area is an important variable in a solar potential analysis [18]. Vector cartographic maps, digital cadastral services, state geographic information systems, digital elevation and digital surface models, and aerial photos are different resources that are widely used in evaluating solar potential [18]. These resources provide required information about building shape, footprint, height, type, location, and other urban features [18]. The need for more detailed city models has led to increasing use of LiDAR point clouds which contains a wealth of Earth surface information [18]. Large volumes of LiDAR data collected in July 2015 , with vegetation in full leaf-on condition, were provided by the city of Lethbridge through the University of Lethbridge, and used to represent the study area in ArcGIS. The resolution of LiDAR data is $1 \mathrm{~m}^{2}$. The city boundary data and a polygon shape file of building footprints provided by the city of Lethbridge were used to determine the extent of the study area and to identify rooftops $[32,35]$.

\section{Processing Lidar data to drive suitable rooftop area for PV application}

LiDAR data are usually provided in LAS format and a defined spatial reference is not typically embedded in them (Fig. 2) [36]. The proper spatial reference information of LAS files that was indicated in the LiDAR metadata was defined. Using LiDAR data, two kinds of high-quality elevation models including digital surface model (DSM) and digital elevation model (DEM) can be produced. First return (surface return) or DSM encompasses elevation information for buildings, tree canopies, and bridges, while ground or bare earth or digital elevation model (DEM) represents the topography $[21,37]$. To analyze the shading, slope, and azimuth (orientation) of each roof segment at a resolution of $1 \mathrm{~m}^{2}$, LiDAR data were processed. The digital surface model (DSM) with a $1 \times 1 \mathrm{~m}$ cell size was created via maximum value interpolation technique to model the high-relief urban area (Fig. 2) [37]. For generating a DSM from LiDAR data, the maximum value is the best technique for biasing the result to higher elevations [37]. Because PV panels are placed on top of buildings, the building footprint data were used to clip DSM $[8,23]$. Before intersecting these two files, a 1-m buffer was applied to building footprint areas [23]. LiDAR data may contain some noise and may not be precise enough close to the roof edges, and thus may be unable to provide an accurate representation of roof borders [23]. As a result, there is no explicit or absolute roof boundary discernible from LiDAR data. Applying this 1-m buffer helped to eliminate noise in LiDAR data [23]. It was assumed that the whole area of rooftops cannot be covered by PV panels and the extent of roof surfaces devoted to the panels is assumed to be bounded by a 1-m-wide perimeter area. This margin area is also required for safety and maintenance purposes [23].

Different methods have been used to extract roof footprints from LiDAR data. For instance, Huang et al. used vegetation information, normalized difference vegetation index (NDVI), from color-infrared image and height information from DSM to recognize building roof surfaces [21]. Chaves and Bahill used an elevation mask to exclude the locations lower than a specific height [38]. To extract building roof 


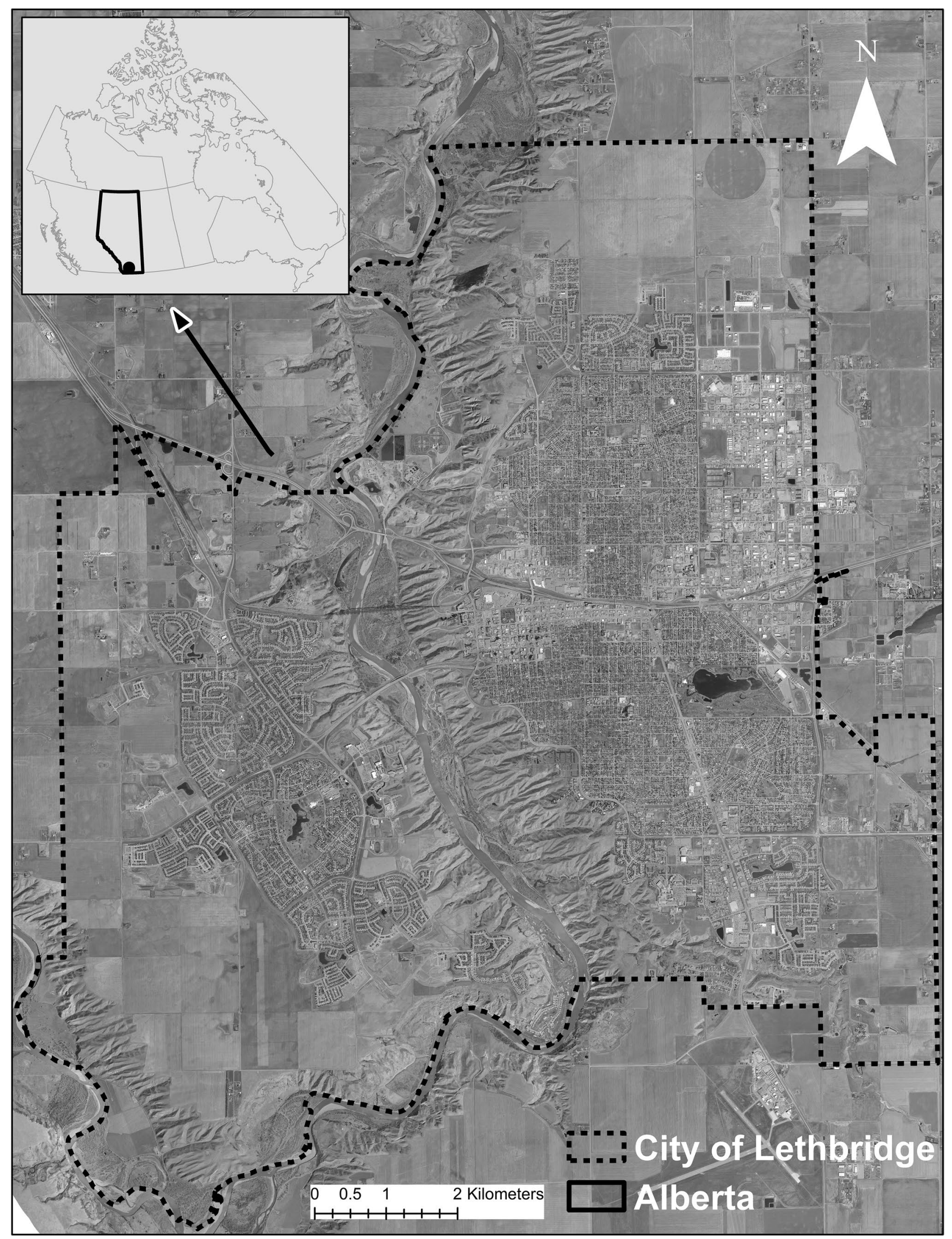

Fig. 1 Study area, the city of Lethbridge [34] 
Table 1 Number of buildings in Lethbridge

\begin{tabular}{lll}
\hline Building type & Number of buildings & $\begin{array}{l}\text { Share of } \\
\text { sectors } \\
(\%)\end{array}$ \\
\hline Residential & 53,545 & 95.8 \\
Industrial & 1207 & 2.16 \\
Commercial & 822 & 1.5 \\
Education & 131 & 0.23 \\
Government & 69 & 0.12 \\
Recreation & 68 & 0.12 \\
Cultural/heritage & 17 & 0.03 \\
Medical & 16 & 0.03 \\
Transportation & 1 & 0.002 \\
Community Center & 1 & 0.002 \\
\hline
\end{tabular}

surfaces from the LiDAR data, DSM was clipped by a building footprint polygon shape file. Most of the buildings are single homes with mainly ridged roofs. Topographic characteristics such as hillshade, slope, and aspect were calculated using the extracted DSM from the LiDAR point cloud [21].

\section{Rooftop slope analysis}

The steepest downhill fall from each cell to its eight surrounding cells (the largest elevation change over distance between each cell and its adjacent cells) was calculated in ArcGIS using the average maximum technique [39]. The slope of each $\mathrm{m}^{2}$ of roof surfaces in the study area was determined. Lower slope values represent flatter planes [39]. Surfaces with a tilt less than $10^{\circ}$ are usually defined as flat planes [8, 23]. PV panels installed on pitched roofs usually have an inclination angle equal to the slope of the roof [17]. On the flat or almost flat roofs, PV panels can be installed with a desired slope [17]. The optimal PV panel tilt angle varies with latitude. PV systems with tilt angles equal to latitude produce more yearly electricity than others, while those with slopes larger than latitude generate more constant energy, but have lower annual production [40]. Lower slopes lead to more electricity production in summer, whereas higher tilt angles induce larger energy generation in winter [40]. In fact, with higher slopes, the difference between summer and winter energy production decreases, and throughout the year the energy flow is more consistent, while with lower slopes, the fluctuation of produced energy during summer and winter is considerably higher, meaning that over the course of a year, generated electricity exhibits a significant seasonal change. Accordingly, a slope classification logic was utilized to organize different rooftop surfaces with various slopes according to their suitability for PV installation (Table 2) [23].
Slope evaluation with LiDAR data is not always precise or perfectly accurate [23]. The calculated slope might vary throughout a surface with a unique actual slope due to noise in the LiDAR data [23]. Noise is generated when light pulses encounter an object which does not belong to the roof surface [23]. To reduce noise and obtain the most accurate results, the majority filter was used [23]. Using this filter, cell slope values were replaced based on the majority of their contiguous neighboring cells [23].

\section{Rooftop Azimuth analysis}

Solar panels oriented towards a specific direction exhibit maximum performance [8]. Azimuth (aspect) identifies the compass direction that the surface slope faces at the installed location. The azimuth in positive degrees was derived from the input elevation data set (the LiDAR-generated DSM) for each square meter of roof area utilizing ArcGIS [8]. Aspect values were measured clockwise, from 0 that defines north to 360 which again indicates north. Flat areas have an aspect value of -1 . The azimuth measurements were categorized into nine classes (Fig. 3) [8]. Next, to eliminate noise, the majority filter was used [23]. Azimuth values are used to detect all roof planes [8]. A roof plane is composed of contiguous areas with the same azimuth [8]. Roof planes were converted to polygons; thereby, individual square meters of roof surfaces were dissolved into homogeneous roof planes [8]. Then, to calculate a single average tilt for each individual roof segment, the Zonal Statistics tool was applied to the slope raster [8].

\section{Shading analysis}

To model the spatio-temporal variation of insolation on different facets of urban surfaces and to determine the unobscured fractions of each roof plane for most of the time, a shading simulation was applied to the city's DSM to illustrate the spatial and temporal variation of the shadows. The gradual movement of shadows cast by nearby features throughout a day influences the performance of PV systems significantly, and makes it of particular importance to consider the variations in length and direction of shadows in PV installments. By running the shading simulation for each daylight hour for March 21 (vernal equinox), June 21 (summer solstice), September 21 (autumnal equinox), and December 21 (winter solstice), the hourly and seasonal variations of shading were assessed [8]. To investigate the illumination pattern over time and to exclude roof segments that are extremely shaded, ArcGIS hillshade capability was employed to generate a shaded relief based on the local 


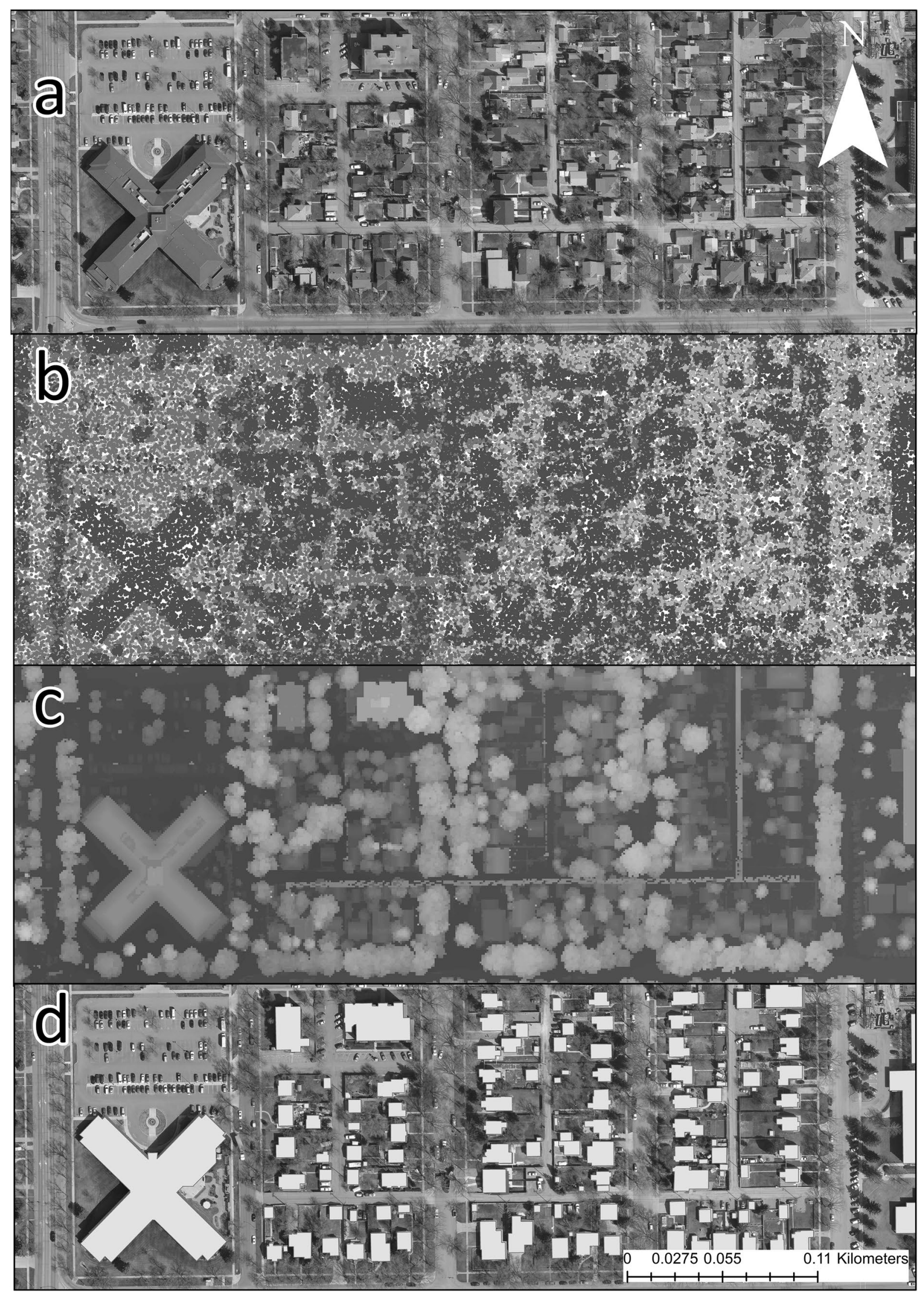

Fig. 2 Spatial layers: a aerial imagery, b LiDAR point clouds, $\mathbf{c}$ DSM, $\mathbf{d}$ building footprint polygons 
Table 2 Slope classes for roof areas [23]

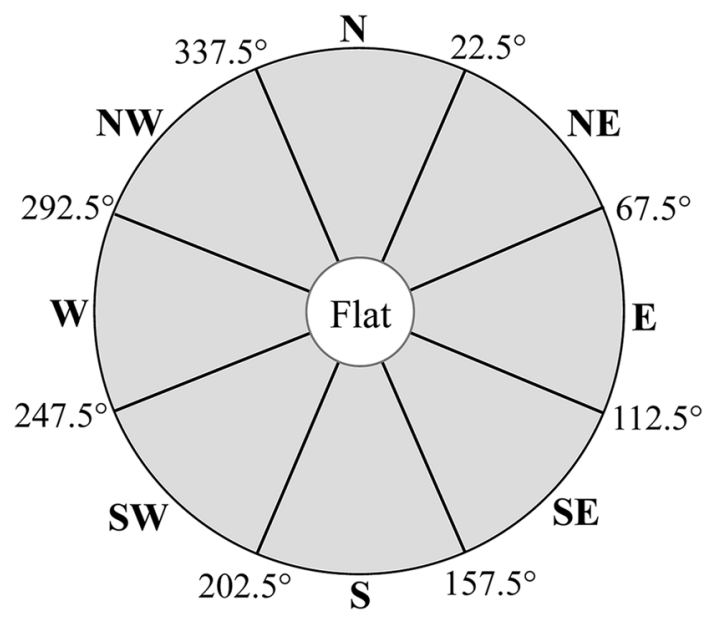

Fig. 3 Rooftop azimuth classes [8]

illumination angle (sun's relative position) and shadows (Fig. 4) [41].

\section{Suitable roof surface selection}

Suitable locations for the placement of PV panels possess particular attributes [38]. Various criteria for selecting suitable roof planes based on their slope (tilt), aspect (azimuth), minimum amount of contiguous area, and received incident solar radiation were applied. Because Lethbridge is located in the northern hemisphere, all roof surfaces oriented towards northwest through northeast $\left(292.5^{\circ}-67.5^{\circ}\right)$ were excluded $[8,21]$. The slope of roof surfaces should be less than $60^{\circ}$, and rooftops larger than $10 \mathrm{~m}^{2}$ were considered to be suitable for placing PV panels $[6,21]$. The smallest practical residential solar system that can exhibit a tangible energy production is a $1.5-\mathrm{kW}$ system $[8,42]$. Such systems require approximately $10 \mathrm{~m}^{2}$ of area [8]. These criteria also exclude objects such as chimneys, dormers, and heating, ventilation, and air-conditioning (HVAC) apparatus located on roofs [43]. In addition, desirable roof surfaces should receive a minimum number of sunlight hours. In hillshade raster, the illumination status of each square meter of rooftops in each hour is illustrated by an integer value ranging from 0 to 255 [41]. At summer solstice, between 9 a.m. and 3 p.m., cells with more than $50 \%$ of the full brightness value were considered not shaded and others with lower brightness were filtered out [23]. By examining a sample of these cells, we found that they have more than $20 \%$ of the maximum illumination at winter solstice between 11 a.m. and 2 p.m. Investigation of the hillshade raster of different months showed that the aforementioned brightness threshold leads to reasonable results. This multi-criteria strategy eliminates unsuitable rooftop areas that lack appealing characteristics, but it is expected that non-optimally tilted and oriented roof planes will also become economically viable and attractive for placing PV panels in the future due to cost reductions and improved efficiency (Fig. 5) [24].

The file of roof segments with appropriate slope and aspect was created, and then run through a dissolve function which merges contiguous polygons with a specific common characteristic to produce continuous suitable areas. Next, the rooftop polygon file was converted to a raster file and reclassified. The reclassified hourly hillshade raster files were combined with the rooftop raster by applying Raster Calculator. Employing Python syntax, Raster Calculator accomplishes Map Algebra expressions consisting of various geoprocessing operators on multiple inputs to create a desirable raster [44]. To evaluate the actual practicable roof expanse and the PV installed (nameplate or nominal or rated) capacity, the projected roof areas were determined from building footprints and used to calculate the oblique area of each suitable roof segment.

\section{Solar resource evaluation}

The solar radiation estimation can be conducted using different solar models, ground-based meteorological stations, or meteorological satellite measurements [25]. Solar resource potential was assessed for the entire study area utilizing solar analyst. Solar analyst uses the DSM to produce global, direct, and diffuse insolation maps for a geographic area [23]. Solar analyst considers the atmospheric effects, latitude and elevation of the region, steepness (slope) and compass direction (aspect), daily and seasonal variation of the sun position, shadows, and topography while ignoring local weather and temperature $[6,17]$. Cloud cover has the largest influence on radiation attenuation in the atmosphere [27]. Solar analyst uses defined default values for the diffuse proportion of global radiation $\left(k_{\mathrm{D}}\right)$ and the ratio of the insolation received at the Earth's surface as direct radiation along the shortest atmospheric path at sea level to the insolation at the upper border of the atmosphere $\left(\tau_{\mathrm{sl}}\right.$, transmittivity), which should be adjusted for local atmospheric conditions $[11,20,45]$. Accordingly, utilizing meteorological measured 

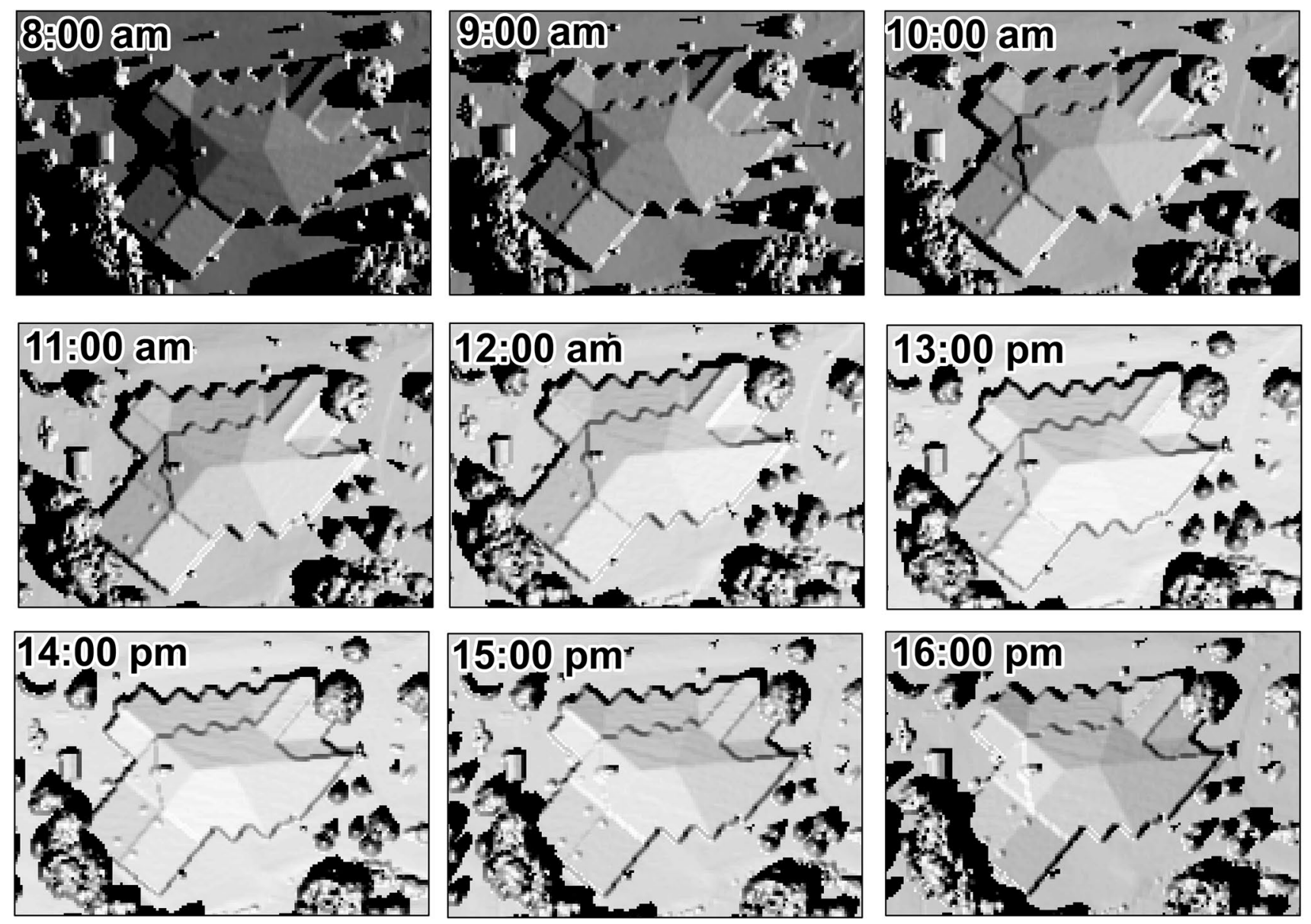

Fig. 4 Hourly illumination and shading pattern example, June 21

data over 5 years from a station (Lethbridge CDA, located at $49^{\circ} 42^{\prime} 0^{\prime \prime} \mathrm{N}, 112^{\circ} 46^{\prime} 60^{\prime \prime} \mathrm{W}$ ) inside the study region and calculating the actual values of required inputs $\left(k_{\mathrm{D}}=0.429\right.$, $\tau_{\mathrm{sl}}=0.589$ ), the effects of cloud cover and local atmospheric conditions have been included. All meteorological data were obtained from Alberta Agriculture and Forestry, Alberta Climate Information Service (ACIS) (https://agriculture.alber ta.ca/acis, retrieved 2016). Instead of $\tau_{\mathrm{sl}}$ in global annual solar radiation calculation, we used $k_{T_{\mathrm{sl}}}$ (the ratio of measured global solar radiation on a horizontal surface against the extraterrestrial radiation at sea level) [11]. Between $11: 30$ and 12:30 $\mathrm{h}$ for each day of the years 2010-2014, the hourly $k_{\mathrm{T}}$ was evaluated for the station [46]. For estimating solar radiation, the annual mean of these $k_{\mathrm{T}}$ values was used. Then, the diffuse fraction of hourly global radiation was estimated utilizing Erbs et al.'s model (Eq. 1) [47]:
Solar analyst algorithm utilizes sea-level transmissivity [48]. Hence, using Eq. $2, k_{\mathrm{T}_{\mathrm{Z}}}$ was adjusted for sea level, where $Z$ represents elevation [46]:

$k_{T_{\mathrm{Z}}}=k_{T_{\mathrm{sl}}}^{\exp \left(-0.000118 z-1.638 \times 10^{-9} z^{2}\right)}$.

Next, zonal statistics was used to average the annual solar radiation values of all individual square meters inside each suitable rooftop segment to identify the roofs' received total solar radiation $\left(\mathrm{Wh} / \mathrm{m}^{2}\right)$.

To assess the accuracy of simulated solar radiation, the results were compared with measured insolation obtained from ACSI for the aforementioned station. The mean bias error (MBE) and the mean absolute bias error (MABE) for comparing the monthly average observed and simulated insolation were calculated (Eq. 3) [49]:

$K_{\mathrm{D}}= \begin{cases}1.0-0.09 k_{\mathrm{T}} ; & k_{\mathrm{T}} \leq 0.22 \\ 0.9511-0.1604 k_{\mathrm{T}}+4.388 k_{\mathrm{T}}^{2}-16.638 k_{\mathrm{T}}^{3}+12.336 k_{\mathrm{T}}^{4} ; & 0.22 \leq k_{\mathrm{T}} \leq 0.80 \\ 0.165 ; & k_{\mathrm{T}}>0.80\end{cases}$ 


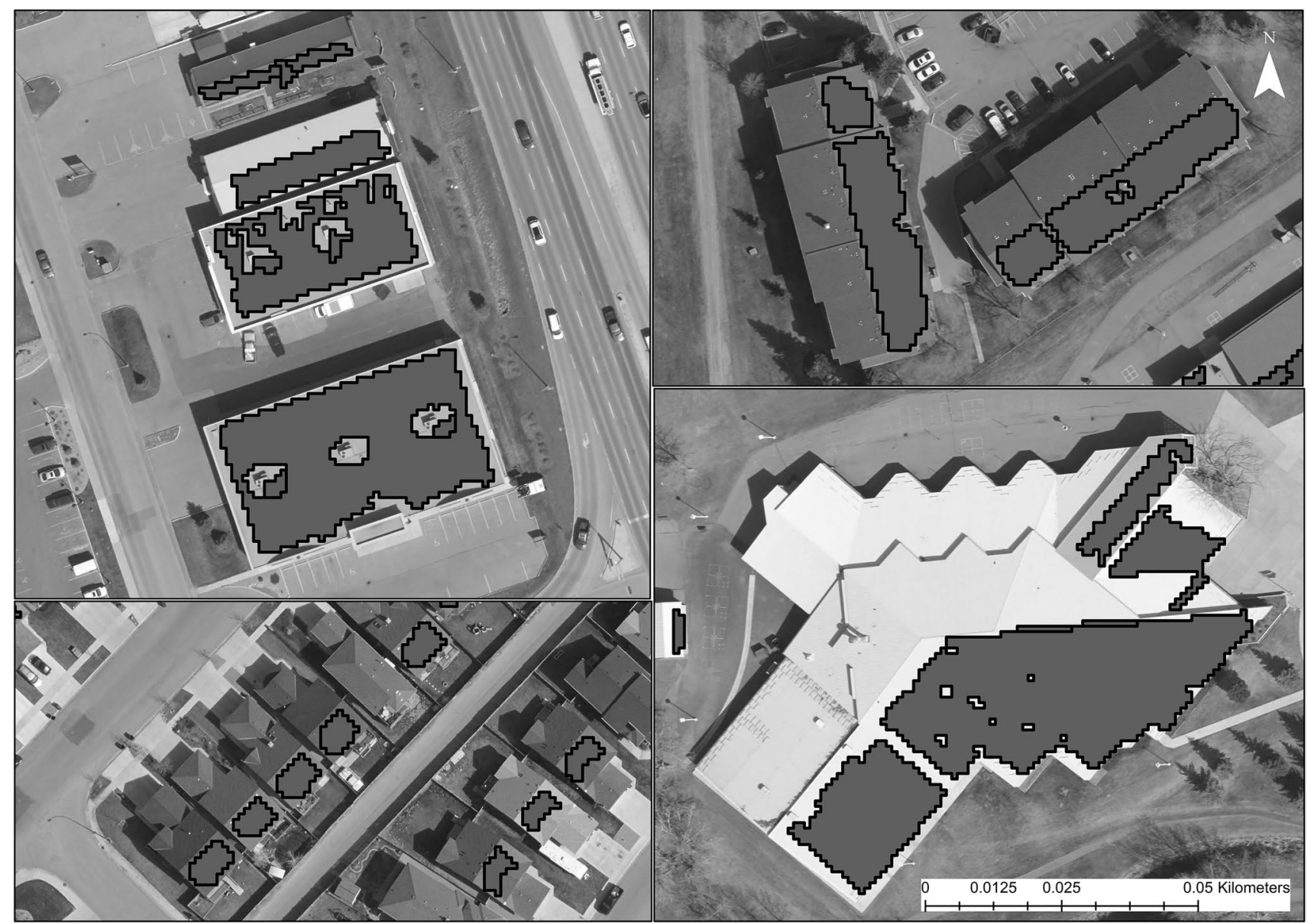

Fig. 5 Examples of suitable rooftop area selection (roof applications such as chimneys have been excluded)

$$
\begin{aligned}
& \mathrm{MBE}=\frac{1}{n} \sum_{i=1}^{n}\left(y_{i}-x_{i}\right), \quad \mathrm{MABE} \\
& =\frac{1}{n} \sum_{i=1}^{n}\left|y_{i}-x_{i}\right|, \quad R^{2}=1-\frac{\sum_{i=1}^{n}\left(x_{i}-y_{i}\right)^{2}}{\sum_{i=1}^{n}\left(x_{i}-\bar{x}\right)^{2}},
\end{aligned}
$$

where $x_{i}, y_{i}, n$, and $\bar{x}$ are the $i$ th measured value, the $i$ th calculated value, the total number of insolation data, and the mean measured global radiation, respectively [49]. MBE illustrates the model's inclination towards radiation overestimation (positive value) or underestimation (negative value) [50]. The coefficient of determination $\left(r^{2}\right)$ derived from regression analysis was used to interpret how accurately the actual data points are approximated by the model and to determine the extent to which the two data sets are in agreement [49]. For 2017 measured radiation, the analysis revealed that $R^{2}$ is 0.98 , which means that the model predicts the insolation very well and there is a very good fit between the two data sets. In addition, the distribution of residuals did not exhibit a strong non-linear relationship of measured and modelled results. In addition, MBE of 5\% and MABE of $12 \%$ were determined, which are in acceptable ranges (Fig. 6, Table 3). MBE and MABE are normalized by the average of the measured radiation. The monthly measured radiation ranges from $174.2 \mathrm{MJ} / \mathrm{m}^{2}$ to $928.6 \mathrm{MJ} / \mathrm{m}^{2}$ with an average equal to $477.8 \mathrm{MJ} / \mathrm{m}^{2}$.

Using default values of ArcGIS leads to $33 \%$ underestimation of radiation (Fig. 7, Table 4), while the employed method induces 5\% overestimation considering 2017 measured data.

Using monthly averaged values of $\mathrm{k}_{\mathrm{D}}$ and $\tau_{\mathrm{sl}}$ obtained over the years 2010-2014 and considering the 2017 measured data, MBE of $1 \%$ and MABE of $9.21 \%$ were determined which are slightly better than the results of utilizing annual $k_{\mathrm{D}}$ and $\tau_{\mathrm{sl}}$ (Table 5 and Fig. 8). However, for annual rooftop PV electricity potential estimation, it seems more practical and sufficiently accurate to use a one set of $k_{\mathrm{D}}$ and $\tau_{s l}$. Hence, the annual values of $k_{\mathrm{D}}=0.429$ and $\tau_{\mathrm{sl}}=0.589$ can be used for solar radiation calculation in the study area. 


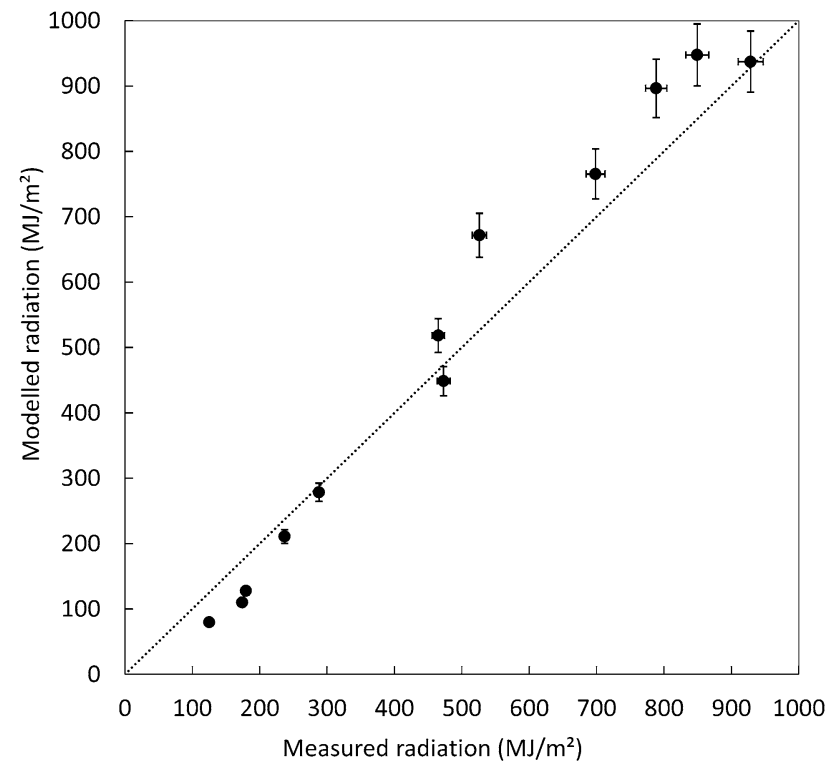

Fig. 6 Observed versus modelled total monthly solar radiation with calculated annual average $k_{\mathrm{D}}$ and $\tau_{\mathrm{sl}}$

Note also that solar analyst does not calculate the reflected component of radiation.

PV panels are usually installed with a desirable tilt angle on flat rooftops; hence, simulated global solar irradiance on horizontal surfaces was converted to insolation on oblique planes. Hourly measured global solar irradiance data obtained from a station in the study region (Lethbridge $\mathrm{CDA}$ ) over 5 years were transferred to tilt planes utilizing transposition and separation models (Perez et al.'s model, and Erbs et al.'s model] considering the reflected component of radiation [47]. A slope factor was extracted from this transposition and was applied to ArcGIS-simulated global horizontal radiation. In this method, roof segments with slopes between $0^{\circ}$ and $10^{\circ}$ have been considered as flat. Based on Perez et al.'s model, the radiation on a tilted surface has three components including beam, diffuse, and ground reflected [47]. The reflected radiation is defined as $I \rho\left(\frac{1-\cos \beta}{2}\right)$, where $I, \rho$, and $\beta$ are the global radiation on a horizontal surface, the diffuse reflectance of the surroundings (albedo coefficient), and the tilt angle of the surface [47]. Solar radiation on south-facing panels increased by about $7 \%$ when the ground reflected component was taken into account, compared with the case when the ground reflected component was ignored ( $\rho$ was set to zero).
Figure 9 shows different stages of LiDAR data processing for an example building with a complex roof surface.

\section{Rooftop PV electricity production simulation}

Electricity output evaluation of a PV system requires the estimation of resource availability, the physically available area, and the technology's performance [10]. The performance capacity of the flat rooftop PV systems is simulated by considering a packing factor which reflects the access space between installed panels required for maintenance purposes and to avoid shading from vicinity panels (row spacing) $[16,51]$. Usually, solar modules require an installation area about 2.5 times greater than their own surface area which means that about $40 \%$ of the suitable flat area is usually covered by solar panels [51]. The ratio of panel area to roof surface for inclined roofs which accounts for necessary module spacing for racking clamps was taken as 98\% [8]. Technical characteristics and assumptions for PVperformance modeling are presented in Table 6 .

Electricity output $E$ is computed by means of the following equation $[14,24]$ :

$E=M_{\mathrm{Irr}} \times A \times \eta \times \mathrm{PR}$,

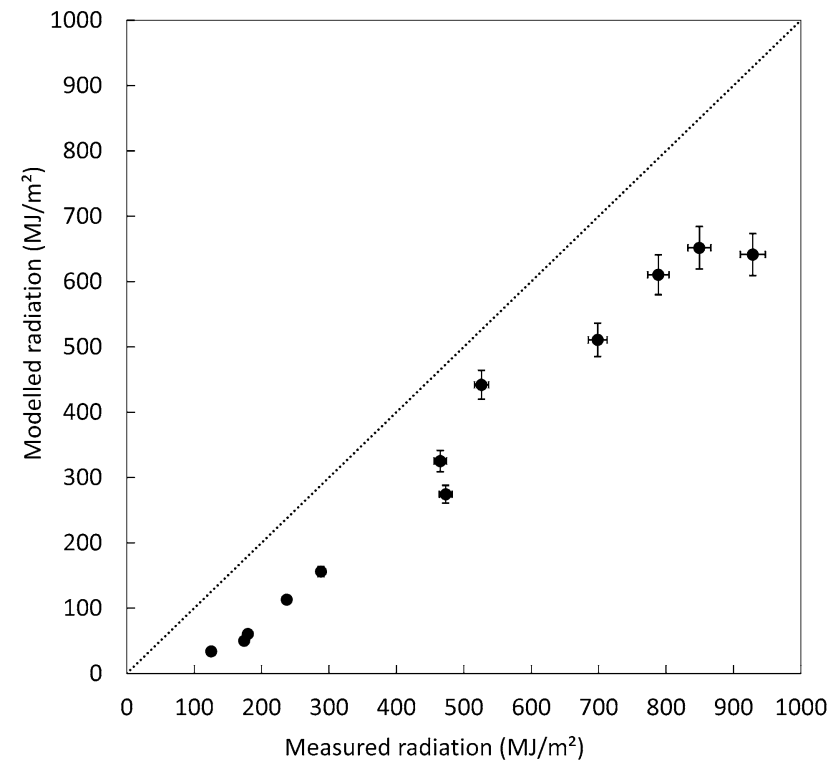

Fig. 7 Observed versus modelled total monthly solar radiation with solar analyst's default $k_{\mathrm{D}}$ and $\tau_{\mathrm{sl}}$

Table 3 Regression relationships between monthly observed and modelled total solar radiations with calculated annual average $\mathrm{k}_{\mathrm{D}}$ and $\tau_{\mathrm{sl}}$

\begin{tabular}{llllllllll}
\hline$y=a+b x$ & Std. error & $t_{\mathrm{a}}$ & $p$ & Std. error $_{\mathrm{b}}$ & $t_{\mathrm{b}}$ & $p$ & $r^{2}$ & MBE & MABE \\
\hline$y=-61.411+1.174 x$ & 30.718 & -1.999 & $<0.001$ & 0.056 & 21.007 & $<0.001$ & 0.989 & 0.050 & 0.120 \\
\hline
\end{tabular}


Table 4 Regression relationships between monthly observed and modelled total solar radiations with solar analyst default $k_{\mathrm{D}}$ and $\tau_{\mathrm{sl}}$

\begin{tabular}{llllllllll}
\hline$y=a+b x$ & Std. error $_{\mathrm{a}}$ & $t_{\mathrm{a}}$ & $p$ & Std. error $_{\mathrm{b}}$ & $t_{\mathrm{b}}$ & $p$ & $r^{2}$ & MBE & MABE \\
\hline$y=-79.842+0.842 x$ & 21.466 & -3.719 & $<0.001$ & 0.039 & 21.560 & $<0.001$ & 0.967 & -0.325 & 0.325 \\
\hline
\end{tabular}

Table 5 Regression relationships between monthly observed and modelled total solar radiations with calculated monthly averaged $k_{\mathrm{D}}$ and $\tau_{\mathrm{sl}}$

\begin{tabular}{llllllllll}
\hline$y=a+b x$ & Std. error & $t_{\mathrm{a}}$ & $p$ & Std. error $_{\mathrm{b}}$ & $t_{\mathrm{b}}$ & $p$ & $r^{2}$ & MBE & MABE \\
\hline$y=-31.769+1.061 x$ & 34.240 & -0.928 & $<0.001$ & 0.062 & 17.038 & $<0.001$ & 0.979 & -0.010 & 0.092 \\
\hline
\end{tabular}

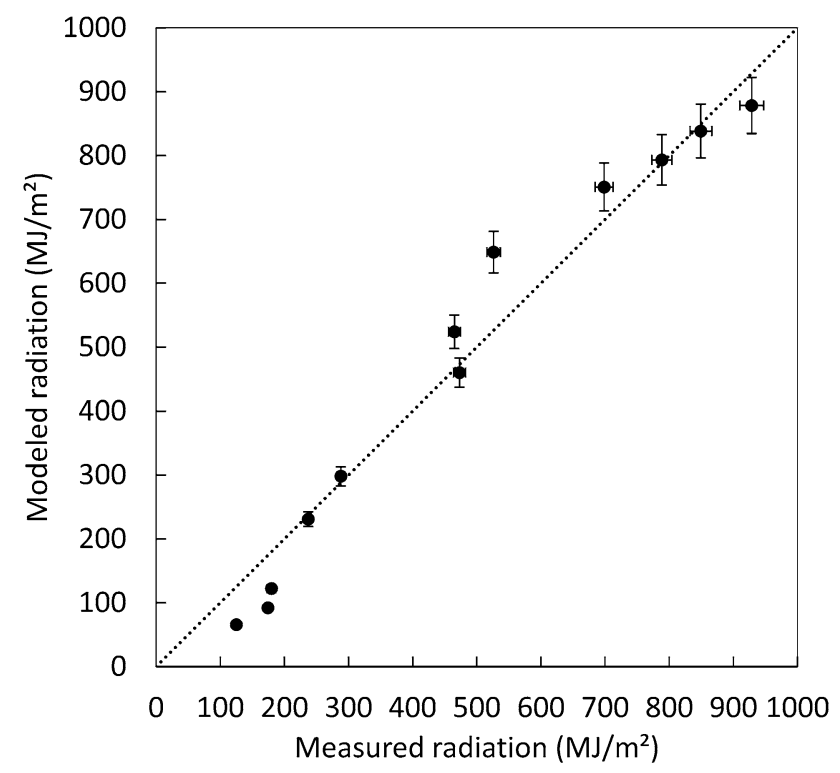

Fig. 8 Observed versus modelled total monthly solar radiation with calculated monthly averaged $k_{\mathrm{D}}$ and $\tau_{\mathrm{sl}}$

where $M_{\text {Irr }}$ is the average irradiation of each suitable rooftop, and $A$ is the actual surface area of each suitable rooftop [24]. Shading simulation being accounted for each rooftop's $M_{\text {Irr }}$ by solar analyst. PR is the performance ratio of an implemented system and is defined as below [53]: resistance in the DC circuit, and DC current ripple and algorithm error caused by the switching converter which performs the maximum power point tracking function contribute in the system losses (Table 7) [54]. PR can be calculated according to Eq. 6 [54]. Furthermore, inverter efficiency $\left(\eta_{\text {inv }}\right)$ usually ranges from 92 to $95 \%$ [55]. Multiplying the PR by the PV module efficiency, the overall system efficiency can be calculated [56]:

$\mathrm{PR}=\eta_{\text {Dust }} \cdot \eta_{\text {mismatch }} \cdot \eta_{\text {DClass }} \cdot \eta_{\text {MPPT }} \cdot \eta_{\text {inv }} \cdot$

Investigating 100 German PV systems' performance, Reich et al. found that, with the help of Germany's cool climate, the PR of some systems exceed 90\% [57]. Given that southern Alberta's solar resources are 30\% better than Germany and considering the latitude similarity between most German cities and southern Alberta, comparable PV system performances are anticipated [40, 58]. In addition, McKenney et al. developed spatial models of global insolation and photovoltaic potential for Canada assuming a PR of 0.75 [40]. In addition, Pelland and Poissant evaluated the potential of building integrated photovoltaics (BIPV) in Canada considering a value of 0.75 for the PR of PV systems [58]. With technology advancements, significant improvement in PV systems' performance and module efficiency has occurred over past years; hence, a PR of $80 \%$ seems attainable in southern Alberta.

$\mathrm{PR}=\frac{\text { Actual AC yield }(\mathrm{kWh} / \text { year })}{\mathrm{DC} \text { power rating }(\mathrm{kW}) \times 8760(\mathrm{~h} / \text { year }) \times \text { Average plane-of-array irradiance }\left(\mathrm{W} / \mathrm{m}^{2}\right) / 1000\left(\mathrm{~W} / \mathrm{m}^{2}\right)}$.

PR compares the actual annual AC energy yield and the expected DC output of an identical ideal and lossless PV system at the same location and can be used to quantify the overall system losses [53]. Actual energy yield, and hence $\mathrm{PR}$, is significantly influenced by actual insolation, various losses including shading losses, module efficiency losses, and system losses [53]. Losses due to accumulation of snow and soil on panels' surface, module parameter mismatch,

\section{Rooftop PV economic potential assessment}

The economic attractiveness of the rooftop PV systems under current market conditions is investigated to determine whether a specific location is profitable for PV installation or not [24]. Most PV potential studies have not considered the economic feasibility of the PV installations, while homeowners and investors install PV facilities when these systems 


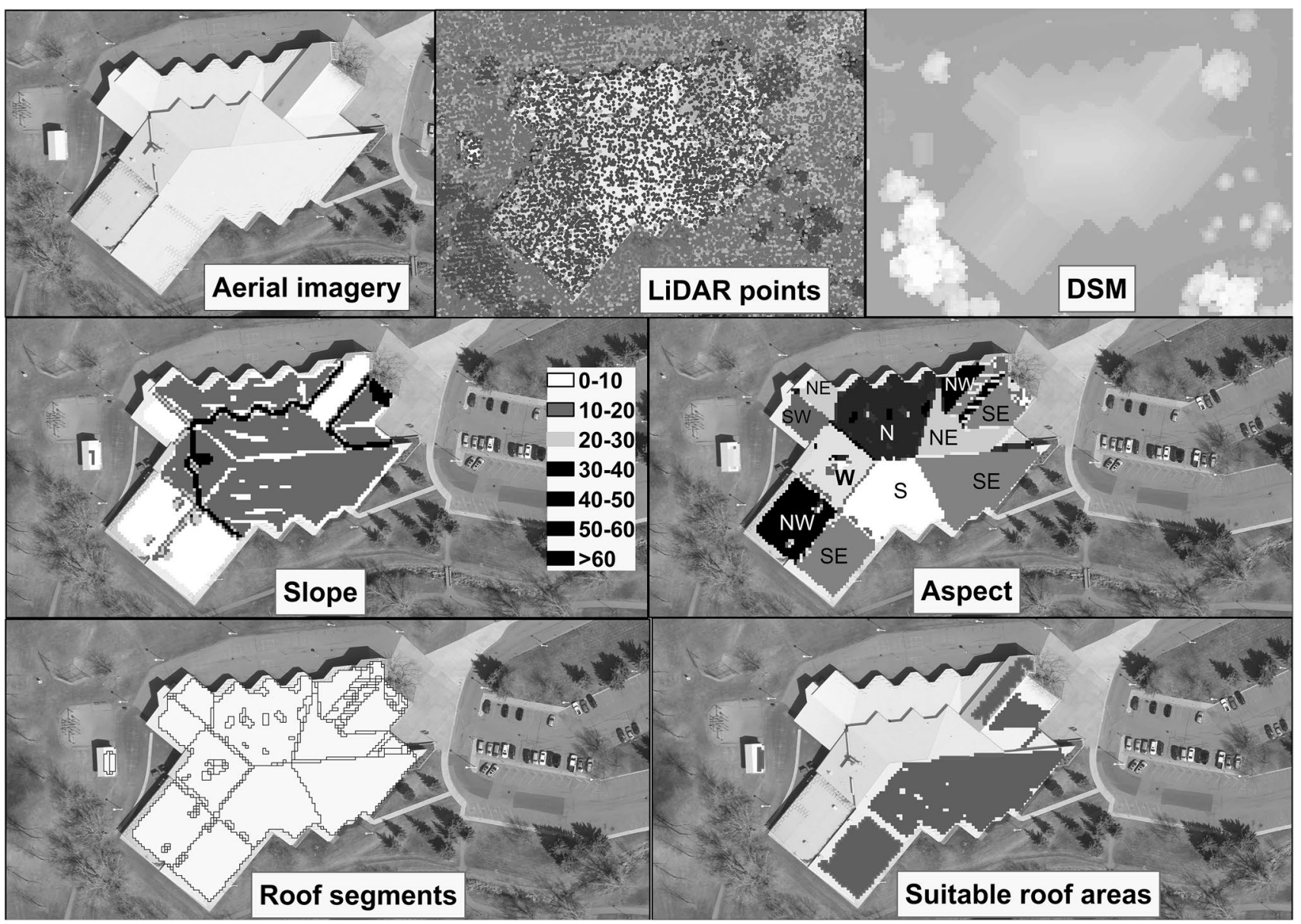

Fig. 9 Various steps of data processing for an example building

Table 6 PV system technical characteristics $[8,14,24,52]$

\begin{tabular}{llll}
\hline Module efficiency $(\eta)$ & Performance ratio (PR) & Inverter efficiency & Module tilt angle for flat roofs \\
\hline $15 \%$ & $80 \%$ & $95 \%$ & Area latitude angle $=49^{\circ}$ \\
Ratio of panel area to suitable rooftop area & System azimuth & \\
0.4 (flat roofs) & 0.98 (inclined roofs) & South facing (flat roofs) & Azimuth classification \\
\hline
\end{tabular}

\section{PV dynamic investment assessment}

\begin{tabular}{ll}
\hline Parameter & Value $(\%)$ \\
\hline$\eta_{\text {Dust }}$ & 96 \\
$\eta_{\text {mismatch }}$ & 95 \\
$\eta_{\text {DClass }}$ & 98 \\
$\eta_{\text {MPPT }}$ & 95 \\
\hline
\end{tabular}

are economically viable [24]. Renewables are not currently cost competitive in all places; hence, it is important to determine the economically viable fraction of solar PV electricity generation potential.
Table 7 Values of

$\eta_{\text {Dust }}, \eta_{\text {mismatch }}, \eta_{\text {DClass }}$ and $\eta_{\text {MPPT }}$ [54]
Net present value (NPV) is utilized to perform an economic potential analysis and to assess the profitability of the solar rooftop projects (Eq. 7) [24]. NPV illustrates the difference between the current value of cash inflows and the present value of cash outflows:

$\mathrm{NPV}=-I_{0}+\sum_{t=1}^{T} \frac{\mathrm{CF}_{t}}{(1+r)^{t}}$

where $t$ is the time of cash flow, $T$ is the total time period or the system life time (25 years), $r$ is the interest rate (2\%), and 
$\mathrm{CF}_{t}\left(\$ /\right.$ year) is the net cash flow at time t (Eq. 8) $[24,59] . i_{\text {deg }}$, $p_{\mathrm{el}}, i_{\mathrm{el}}, c_{\mathrm{op}}$, and $i_{\mathrm{op}}$ are the annual degradation rate of generated electricity ( $0.25 \% / y e a r)$, average electricity price, annual increase in generated electricity price, operating cost, and annual increase in operating cost, respectively (Eq. 8) [24]:

$\mathrm{CF}_{t}=E_{\mathrm{a}} \times\left(1-i_{\mathrm{deg}}\right)^{t} \times p_{\mathrm{el}} \times\left(1+i_{\mathrm{el}}\right)^{t}-c_{\mathrm{op}} \times\left(1+i_{\mathrm{op}}\right)^{t}$.

In Alberta, from 2013 to 2017, the average increase in the consumer price index of all items such as food, shelter, and transportation was $1.56 \%$; hence, $i_{\text {op }}$ was set to $1.56 \%$ [60]. In Lethbridge, the electricity price varies, and with higher electricity prices, solar PV systems become more feasible. While the average power price has been $7.3 \notin / \mathrm{kWh}$ from 2012 to 2018, great changes in regulated electricity rates have been occurring historically [61]. Other fees that are charged on electricity bills may increase as well; for instance, average transmission rate in 2027 is forecasted to be about $42 \$$ / MWh which is 33\% more than that in 2018 [60, 62, 63]. Solar energy generation can reduce the energy charge, the variable portion of distribution, and the transmission charge on electricity bills [63]. $p_{\mathrm{el}}, i_{\mathrm{el}}$, and $c_{\mathrm{op}}$ are assumed to be $0.08 \$ / \mathrm{kWh}, 3.5 \%$, and $15 \$ / \mathrm{kW} / \mathrm{year}$. There is a $\$ 36$ million rebate program introduced by the government of Alberta for installing solar PV on residential and commercial buildings aiming to offset up to $30 \%$ of residential solar installation costs and up to $25 \%$ of solar installation costs for businesses and non-profits [64]. We assumed that $25 \%$ of the capital costs for all installations would be covered by this program.

Generated solar electricity $E_{\mathrm{a}}(\mathrm{kWh} /$ year) provides cash inflows, and in an economically feasible system, the related electricity revenue surpasses all upfront capital costs $\mathrm{I}_{0}$ and maintenance and operational expenditures over the system's lifetime [24]. A PV system is economically attractive when its NPV is larger than zero [24]. In 2016, the residential grid-connected rooftop PV systems (up to $10 \mathrm{~kW}$ ), commercial grid-connected rooftop PV systems (between 10 and $250 \mathrm{~kW}$ ), and industrial grid-connected rooftop PV systems (above $250 \mathrm{~kW}$ ) cost between 3 and $3.5 \mathrm{CAD} \$ / \mathrm{W}$, 2.5-3 CAD $\$ / \mathrm{W}$, and 2-2.5 CAD $\$ / \mathrm{W}$, respectively [65]. Up to a $12.5 \%$ decline in PV system prices occurred from 2015 to 2016 [65]. Therefore, the upfront investments for $3 \mathrm{~kW}$, $10 \mathrm{~kW}$, and $250 \mathrm{~kW}$ PV system sizes have been assumed to be $2680(\$ / \mathrm{kW}), 2200(\$ / \mathrm{kW})$, and $1760(\$ / \mathrm{kW})$, respectively, applying a $12 \%$ reduction to the 2016 system prices [65]. Based on these system installment costs, the following relationship between system size $P(\mathrm{~kW})$ and investment $I_{0}$ $(\$ / \mathrm{kW})$ was created to calculate the specific investment for other rooftop PV system sizes [24]:

$I_{0}=2877.2 \times P^{-0.064}$

Utilizing Eq. 9, the initial investment cost for the midpoint of each system size class presented in Table 8 has been calculated [24]. For systems larger than $50 \mathrm{~kW}$ and smaller than $5 \mathrm{~kW}$, the midpoints were set to $60 \mathrm{~kW}$ and $3 \mathrm{~kW}$.

\section{Results and discussion}

Applying the preceding method to the city of Lethbridge, 38,496 suitable rooftop segments with a total actual area of about $2,372,000 \mathrm{~m}^{2}$ were identified which cover approximately $30 \%$ of the total roof area. The accuracy of the rooftop segment selection has been examined by analyzing and investigating several buildings' rooftop areas using the region's aerial image. The individual suitable segments belong mostly to residential (about $83 \%$ ) and commercial (about $9 \%$ ) buildings, providing about $48 \%$ and $20 \%$ of the suitable area, respectively (Fig. 10 and Table 9). Most of the segments are flat or have a slope less than $20^{\circ}$ (about $91 \%$ of them or $84 \%$ of the suitable area). Low slope and flat roofs allow us to install PV panels with the most effective tilt angle [23].

While industrial and commercial buildings account for just about $3 \%$ and $4 \%$ of the flat individual segments, they constitute the largest portion of the suitable flat area $\left(\mathrm{m}^{2}\right)$, about $22 \%$ and $18 \%$ of the available flat area, respectively, demonstrating the importance of these sectors' engagement in developing a successful solar PV industry in cities (Table 9). Furthermore, rooftop PV installation by homeowners can boost the urban solar electricity generation significantly, because residential buildings with roof pitch between $10^{\circ}$ and $20^{\circ}$ account for more than $25 \%$ of the total suitable roof area (about half of the segments), which is the highest share among various building types and slope classes (Table 9).

Some building rooftops have more than one suitable segment, especially those with complex structure. After combining multiple suitable segments of individual buildings' rooftops, it was found that about $48 \%$ of the all buildings possess a suitable roof plane which could host PV systems (26,959 buildings). About $94 \%$ of these buildings are residential (Fig. 11).

The majority of the suitable rooftop planes of residential buildings (45\% of them) have an area between 20 and $50 \mathrm{~m}^{2}$,

Table 8 Initial investment cost of PV system classes derived from Eq. 9

\begin{tabular}{ll}
\hline System size $(\mathrm{kW})$ & $\begin{array}{l}\text { Install } \\
\text { cost }(\$ / \\
\mathrm{kW})\end{array}$ \\
\hline$P \leq 5$ & 2640 \\
$5<P \leq 10$ & 2600 \\
$10<P \leq 20$ & 2400 \\
$20<P \leq 50$ & 2300 \\
$P>50$ & 2200 \\
\hline
\end{tabular}




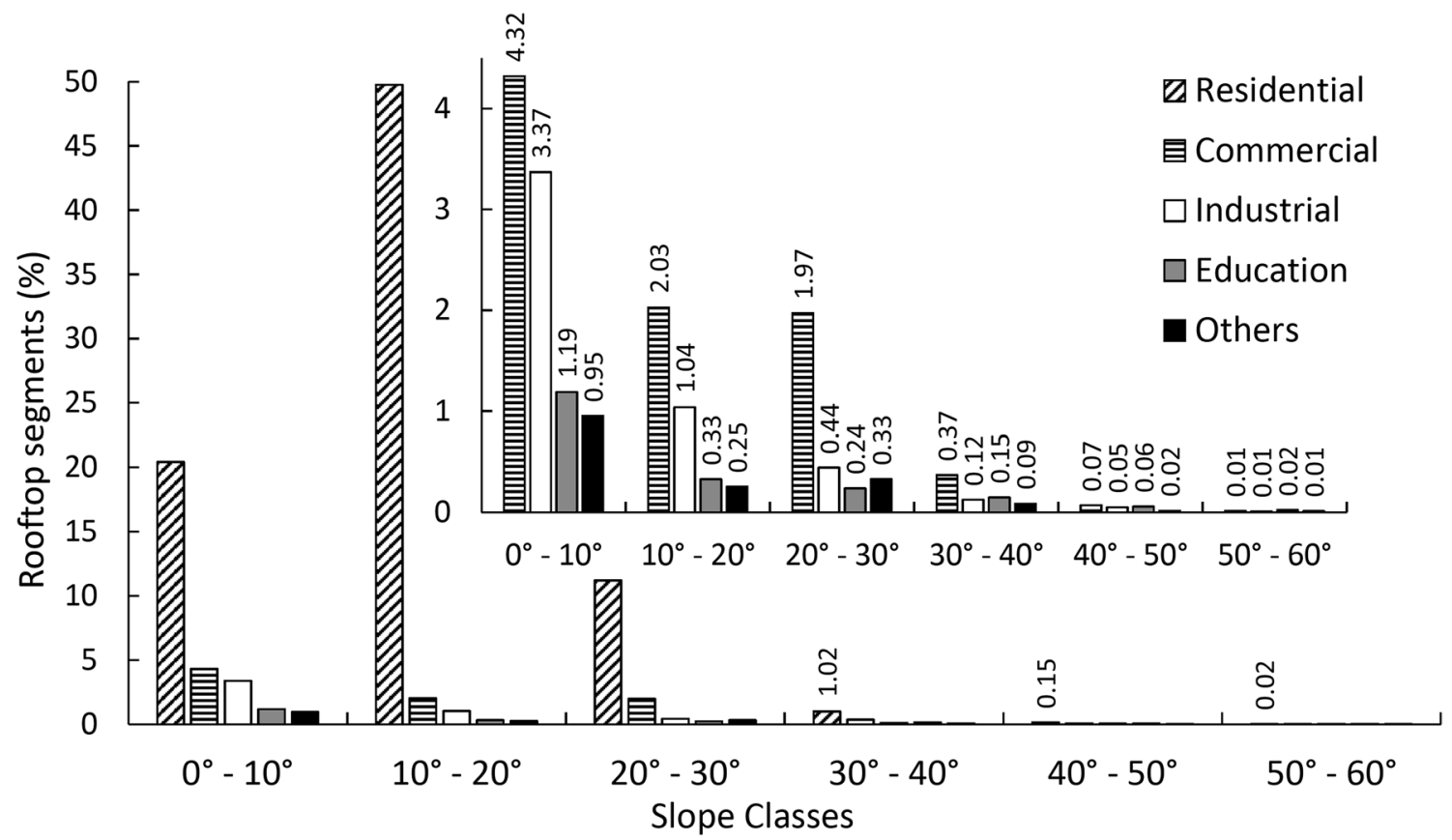

Fig. 10 Percentage of rooftop segments in different slope classes

Table 9 Suitable rooftop segment area $\left(\mathrm{m}^{2}\right)$ and its percentage by building type and slope classes

\begin{tabular}{|c|c|c|c|c|c|c|c|c|c|c|c|c|c|c|}
\hline \multirow[t]{3}{*}{ Building type } & \multicolumn{14}{|c|}{ Slope classes } \\
\hline & \multicolumn{2}{|l|}{$0^{\circ}-10^{\circ}$} & \multicolumn{2}{|l|}{$10^{\circ}-20^{\circ}$} & \multicolumn{2}{|l|}{$20^{\circ}-30^{\circ}$} & \multicolumn{2}{|c|}{$30^{\circ}-40^{\circ}$} & \multicolumn{2}{|c|}{$40^{\circ}-50^{\circ}$} & \multicolumn{2}{|c|}{$50^{\circ}-60^{\circ}$} & \multicolumn{2}{|l|}{ Total area } \\
\hline & $\overline{m^{2}}$ & $\%$ & $m^{2}$ & $\%$ & $m^{2}$ & $\%$ & $\overline{m^{2}}$ & $\%$ & $\overline{m^{2}}$ & $\%$ & $\overline{m^{2}}$ & $\%$ & $m^{2}$ & $\%$ \\
\hline Residential & 368,544 & 15.54 & 598,017 & 25.21 & 163,377 & 6.89 & 9155 & 0.39 & 1066 & 0.04 & 125 & 0.01 & 1140,285 & 48.07 \\
\hline Commercial & 414,781 & 17.49 & 26,845 & 1.13 & 16,614 & 0.70 & 2825 & 0.12 & 508 & 0.02 & 99 & 0.00 & 461,673 & 19.46 \\
\hline Industrial & 513,397 & 21.64 & 22,403 & 0.94 & 4000 & 0.17 & 1130 & 0.05 & 470 & 0.02 & 132 & 0.01 & 541,531 & 22.83 \\
\hline Education & 109,708 & 4.62 & 9595 & 0.40 & 2306 & 0.10 & 1390 & 0.06 & 451 & 0.02 & 294 & 0.01 & 123,745 & 5.22 \\
\hline Others & 94,299 & 3.98 & 4489 & 0.19 & 4496 & 0.19 & 1340 & 0.06 & 185 & 0.01 & 121 & 0.01 & 104,932 & 4.42 \\
\hline Total area & 1500,729 & 63.26 & 661,349 & 27.88 & 190,794 & 8.04 & 15,840 & 0.67 & 1066 & 0.11 & 772 & 0.03 & $2,372,165$ & \\
\hline
\end{tabular}

while most of the commercial and industrial building's suitable rooftops fall between 500 and $1000 \mathrm{~m}^{2}$ (Fig. 12). Around $13,22,49$, and $32 \%$ of the commercial, industrial, education, and other buildings with suitable rooftops have a PV appropriate roof surface larger than $1000 \mathrm{~m}^{2}$ and smaller than $22,000 \mathrm{~m}^{2}$, respectively (Fig. 12). Suitable rooftops larger than $22,000 \mathrm{~m}^{2}$ exist in education and commercial sectors (Fig. 12).

Residential buildings with suitable rooftops mostly (about 90\%) can accommodate PV systems with a size less than $10 \mathrm{~kW}$, while suitable rooftops of commercial, industrial, education, and other building types demonstrate larger system capacity (Fig. 13). For instance, while just $0.09 \%$ of the suitable residential rooftops can host PV systems larger than $100 \mathrm{~kW}$, around $45 \%$ of the education buildings with suitable rooftops can provide sufficient space for rooftop PV systems larger than $100 \mathrm{~kW}$ (Fig. 13).

The identified suitable surfaces provide enough area for installing approximately $218 \mathrm{MW}_{\mathrm{p}}$ of rooftop PV systems, with residential buildings accounting for about half of the installed capacity. Based on the computed solar radiation, this installment could generate around $301 \pm 29 \mathrm{GWh}$ of solar electricity annually (Fig. 14). Most of this electricity would be produced by residential buildings' rooftop (about 57\%) (Fig. 14). Industrial and commercial buildings are the second and third largest potential contributors to rooftop PV energy production (Fig. 14). Combining all uncertainties in various stages of the system yield evaluation, a total of 9.5\% uncertainty in solar PV energy output calculation is estimated [66]. In 2015, in Lethbridge, electricity usage per 
Fig. 11 Percentage (\%) of the different building sectors with suitable roof surface for PV installment
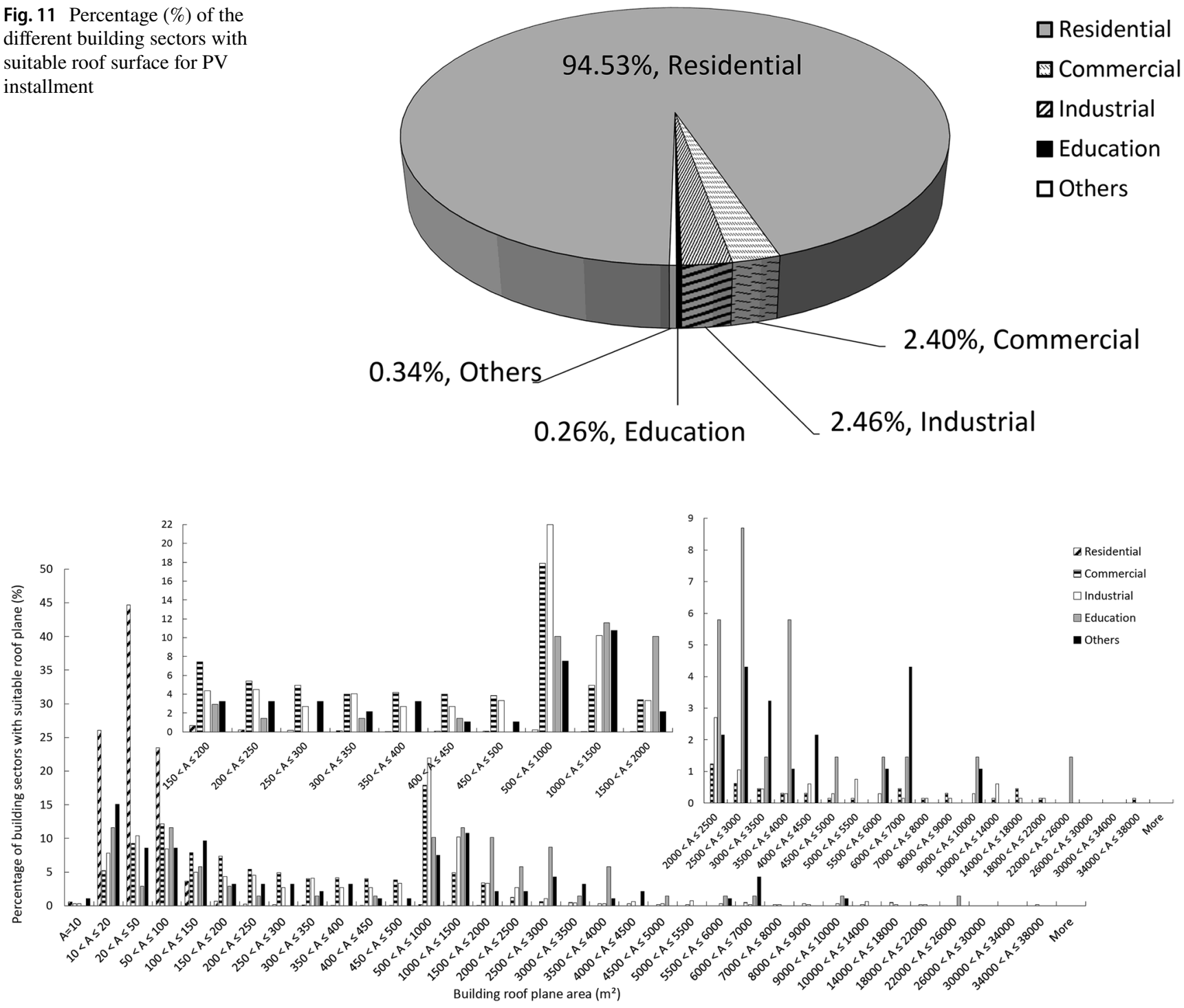

Fig. 12 Area histogram of buildings' suitable roof plane for PV installment

person (for all sectors) was $8.2 \mathrm{MWh}$ [67]. This consumption is lower than provincial and national average electricity consumption and recently has not changed significantly from year to year [67]. Considering the city's population in 2016, the estimated rooftop PV electricity would enable the city to offset almost $38 \%$ of its annual electricity consumption.

Capacity factor $(\mathrm{CF})$, which shows the difference between the actual performance of a PV system and the energy output of an ideal and lossless PV system with alike rated capacity receiving constant irradiance $\left(1000 \mathrm{~W} / \mathrm{m}^{2}\right)$, is used to compare different power systems' potential in producing energy [53]. For instance, typical yearly capacity factors for hydropower plants, natural gas combined cycle plants, coal power plants, and wind plants are about $40,44,64$, and $31 \%$, respectively [53]. System energy yield is proportional to the capacity factor, where capacity factor is defined as [53]

$$
\mathrm{CF}=\frac{\text { Actual AC yield }(\mathrm{kWh} / \text { year })}{\text { DC peak power rating }(\mathrm{kW}) \times 8760(\mathrm{~h} / \text { year })} .
$$

The average capacity factor of the distinguished rooftop systems is about $16 \pm 1.5 \%$, which is very promising for this urban region.

The NPV graphs for system size classes presented in Table 8 and various electricity output level are delineated in Fig. 15 to indicate annual electricity threshold for profitable systems.

Systems with an initial investment of $2640 \$ / \mathrm{kW}$ need to generate about $994 \mathrm{kWh} / \mathrm{kW} /$ year to become economically viable (Fig. 15, Table 10). The initial cost of systems with $2200 \$ / \mathrm{kW}$ investment will be compensated over their lifetime if they produce at least $854 \mathrm{kWh} / \mathrm{kW} / \mathrm{year}$ (Fig. 15, 


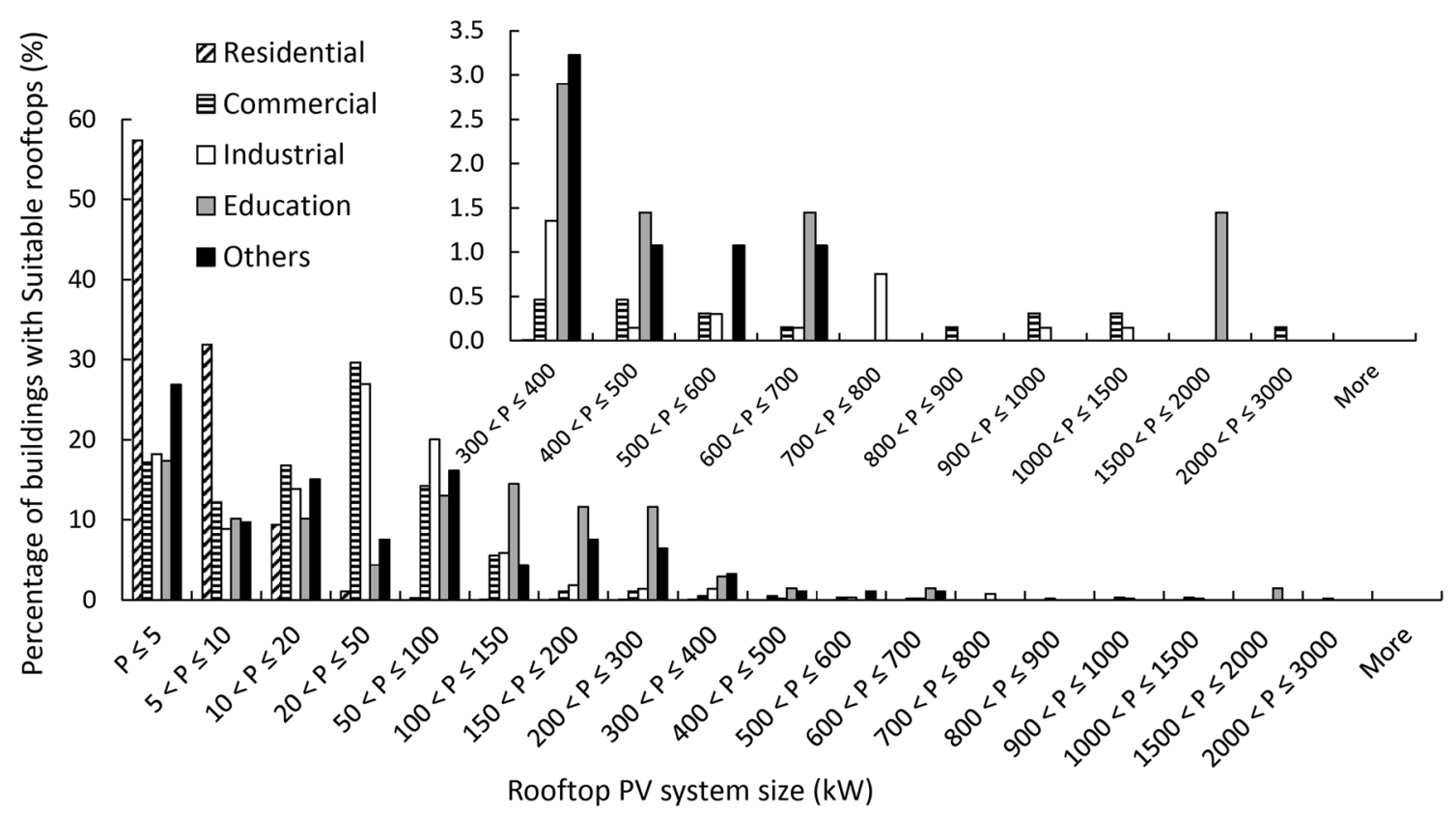

Fig. 13 PV system size histogram of rooftops for different building types

Fig. 14 Rooftop PV electricity potential generation by different building sectors

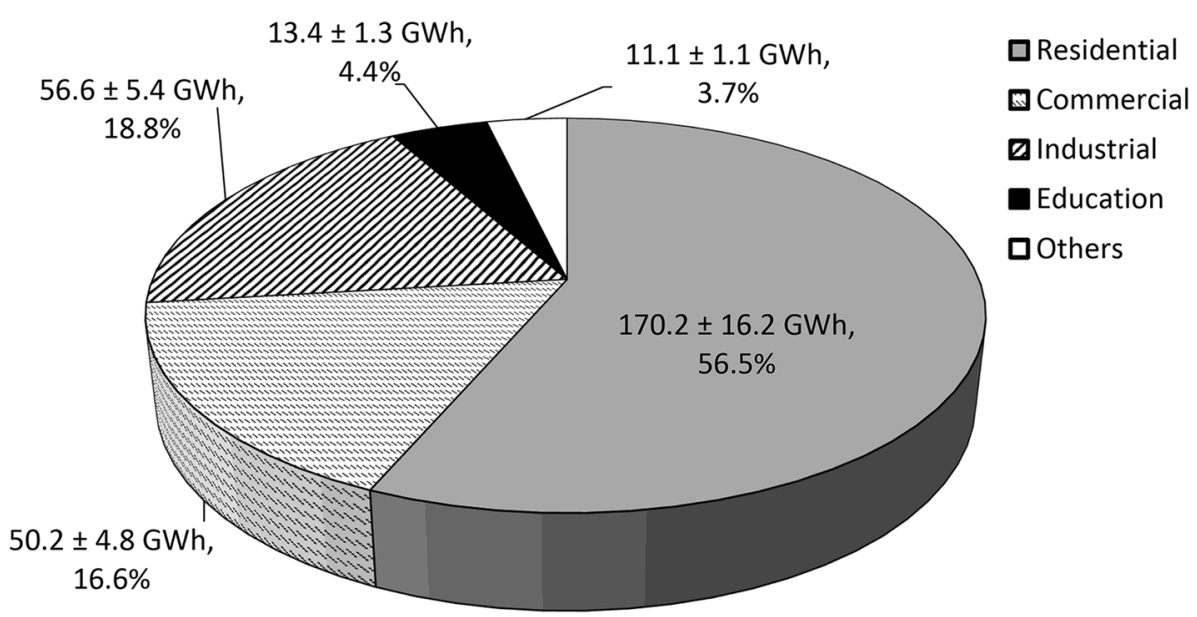

Table 10). Based on NPV graphs, about $96 \%$ of the identified suitable rooftop systems are profitable. Small systems occupying small areas are the most likely to fail to be economically justified. However, with more declined PV costs and improved efficiencies, small areas can achieve a higher packing factor, produce more energy, and become economically attractive.

Recently, the Climate Leadership Plan was introduced by the provincial government, with a goal of ending the use of coal for electricity production by 2030 and utilizing more renewable sources [68]. According to this plan, $5000 \mathrm{MW}$ of new renewable energy capacity will be built by 2030 , with renewables to supply $30 \%$ of the electricity demand which can lead to a significant growth in clean energy investment [68].

\section{Conclusion}

Rising climate change risks and global sustainability challenges along with the significant decreases in costs of renewables have led to recognition of solar electricity systems as major parts of mitigation strategies [5]. Providing end users with a self-managed, usable energy source with minimal operation and maintenance costs, rooftop PV is distinct among low-carbon technologies [9]. Here, an exhaustive rooftop PV potential assessment in an urban area has been 
Fig. 15 NPV graphs for different system size classes versus annual electricity yield

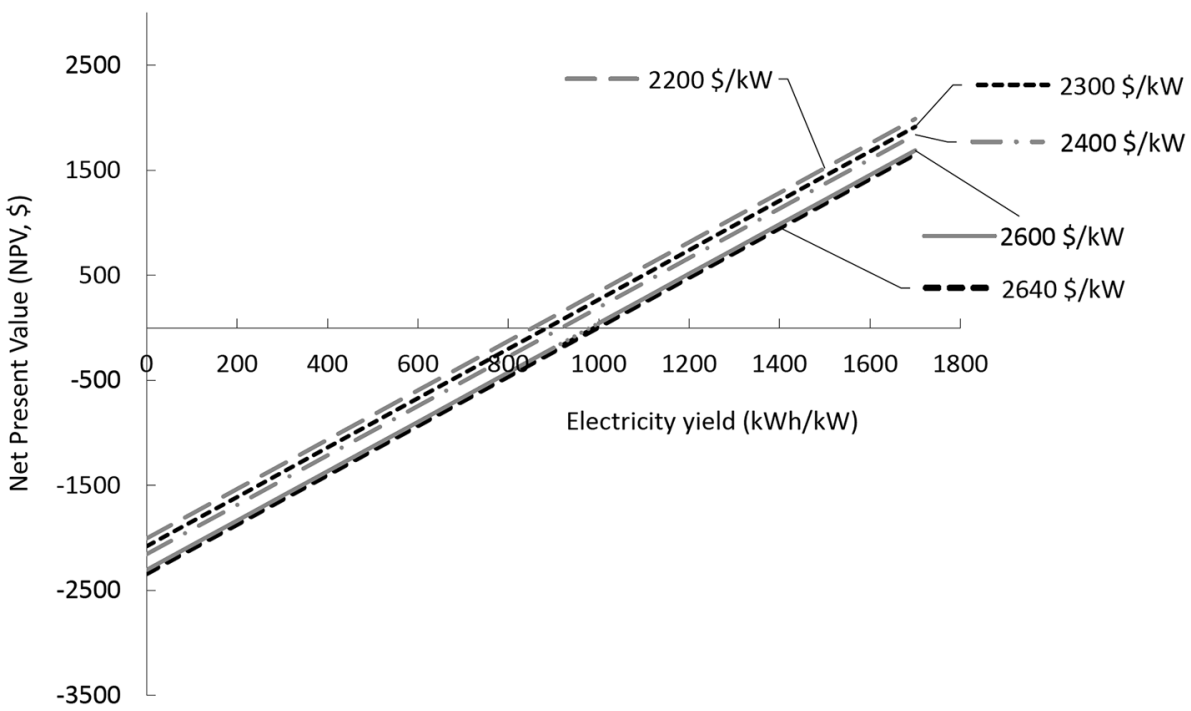

Table 10 Minimum (kWh/kW/year) solar energy production for $\mathrm{NPV}=0$

\begin{tabular}{ll}
\hline System capital cost & $\begin{array}{l}\text { Minimum }(\mathrm{kWh} / \mathrm{kW} / \mathrm{year}) \text { solar } \\
\text { energy production for NPV }=0\end{array}$ \\
\hline 2640 & 994 \\
2600 & 981 \\
2400 & 917 \\
2300 & 886 \\
2200 & 854 \\
\hline
\end{tabular}

conducted to fill a gap in the available public information about the potential of such systems. Alberta's electricity generation sector currently relies heavily on fossil fuels, and coal in particular, producing approximately $17 \%$ of the province's annual GHG emissions in 2015 [68]. To achieve the goal of zero emissions from coal-based electricity production of the Alberta climate plan by 2030, some supporting programs such as "Residential and Commercial Solar Program" and "Alberta Municipal Solar Program" have been established to stimulate the PV system installation on buildings and municipal facilities [68]. In response to this great movement towards more renewable energy sources, this study tries to present an effective and scalable methodology for simulating the insolation resource and rooftop solar PV energy and economic potential in an urban area in Southern Alberta. LiDAR data and ArcGIS were employed to identify suitable rooftops for PV installation and solar analyst simulation engine was applied and adjusted based on data characterizing the local environment to accurately assess the region's insolation resource. Precise solar radiation resources assessment in a large area like an urban area is always challenging; hence, a new method was developed to calculate solar radiation using ArcGIS. In addition, the slope of PV modules installed on flat roofs and the reflected radiation component have been taken into account. Finally, utilizing market prices and dynamic investment methods, the economic potential of rooftop PV systems was investigated. Results illustrated that rooftop PV has a great potential to offset the city's energy demand. This paper tries to increase the awareness about the characteristics and economics of rooftop PV in the study area which is vital to more renewable energy deployment. The results of this research can assist investors in energy and building sectors and accelerate an informed transition towards a more sustainable future.

Acknowledgements Financial and data support provided by Mitacs Program (Canada) in cooperation with NOVUS Environmental, Guelph, Ontario, the University of Lethbridge, the City of Lethbridge, and the Alberta Climate Information Service (https://agriculture.alber ta.ca/acis) are much appreciated.

\section{Compliance with ethical standards}

Conflict of interest On behalf of all authors, the corresponding author states that there is no conflict of interest.

Open Access This article is distributed under the terms of the Creative Commons Attribution 4.0 International License (http://creativeco mmons.org/licenses/by/4.0/), which permits unrestricted use, distribution, and reproduction in any medium, provided you give appropriate credit to the original author(s) and the source, provide a link to the Creative Commons license, and indicate if changes were made.

\section{References}

1. van der Hoeven, M.: Energy and climate change-world energy outlook special report. Int. Energy Agency (2015)

2. Mueller, S., Frankl, P., Sadamori, K.: Next Generation Wind and Solar Power from Cost to Value. International Energy Agency, Paris (2016) 
3. Appavou, F., Brown, A., Epp, B., Leidreiter, A., Lins, C., Murdock, H.E., Musolino, E., Petrichenko, K., Farrell, T.C., Krader, T.T.: Renewables 2017 global status report. In. Tech. Rep., Renewable Energy Policy Network for the 21st Century (REN21) (2017)

4. IRENA: Renewable Energy in Cities. In. International Renewable Energy Agency (IRENA), Abu Dhabi. www.irena.org (2016)

5. Castellanos, S., Sunter, D.A., Kammen, D.M.: Rooftop solar photovoltaic potential in cities: how scalable are assessment approaches? Environ. Res. Lett. 12(12), 125005 (2017)

6. Gooding, J., Edwards, H., Giesekam, J., Crook, R.: Solar City indicator: a methodology to predict city level PV installed capacity by combining physical capacity and socio-economic factors. Sol. Energy 95, 325-335 (2013)

7. Kammen, D.M., Sunter, D.A.: City-integrated renewable energy for urban sustainability. Science 352(6288), 922-928 (2016)

8. Gagnon, P., Margolis, R., Melius, J., Phillips, C., Elmore, R.: Rooftop Solar Photovoltaic Technical Potential in the United States. A Detailed Assessment. National Renewable Energy Lab. (NREL), Golden, CO, USA (2016)

9. Strupeit, L., Palm, A.: Overcoming barriers to renewable energy diffusion: business models for customer-sited solar photovoltaics in Japan, Germany and the United States. J. Clean. Prod. 123, 124-136 (2016)

10. Izquierdo, S., Rodrigues, M., Fueyo, N.: A method for estimating the geographical distribution of the available roof surface area for large-scale photovoltaic energy-potential evaluations. Sol. Energy 82(10), 929-939 (2008)

11. Mirmasoudi, S., Byrne, J., Kroebel, R., Johnson, D., MacDonald, R.: A novel time-effective model for daily distributed solar radiation estimates across variable terrain. Int. J. Energy Environ. Eng. 9(4), 383-398 (2018)

12. Kanters, J., Davidsson, H.: Mutual shading of PV modules on flat roofs: a parametric study. Energy Proc. 57, 1706-1715 (2014)

13. Ordóñez, J., Jadraque, E., Alegre, J., Martínez, G.: Analysis of the photovoltaic solar energy capacity of residential rooftops in Andalusia (Spain). Renew. Sustain. Energy Rev. 14(7), 2122-2130 (2010)

14. International Energy Agency (IEA): Energy Technology Perspectives, Annex H- Rooftop Solar PV Potential in Cities. International Energy Agency. www.iea.org (2016)

15. Denholm, P., Margolis, R.: Supply Curves for Rooftop Solar PVGenerated Electricity for the United States. National Renewable Energy Lab (NREL) (2008)

16. Anderson, K.H., Coddington, M.H., Kroposki, B.D.: Assessing technical potential for city PV deployment using NREL's in my backyard tool. In: Photovoltaic Specialists Conference (PVSC), 2010 35th IEEE 2010, pp. 001085-001090 (IEEE)

17. Verso, A., Martin, A., Amador, J., Dominguez, J.: GIS-based method to evaluate the photovoltaic potential in the urban environments: the particular case of Miraflores de la Sierra. Sol. Energy 117, 236-245 (2015)

18. Martín, A.M., Domínguez, J., Amador, J.: Applying LIDAR datasets and GIS based model to evaluate solar potential over roofs: a review. AIMS Energy 3(3), 326-343 (2015)

19. Singh, R., Banerjee, R.: Estimation of rooftop solar photovoltaic potential of a city. Sol. Energy 115, 589-602 (2015)

20. Jakubiec, J.A., Reinhart, C.F.: A method for predicting city-wide electricity gains from photovoltaic panels based on LiDAR and GIS data combined with hourly Daysim simulations. Sol. Energy 93, 127-143 (2013)

21. Huang, Y., Chen, Z., Wu, B., Chen, L., Mao, W., Zhao, F., Wu, J., Wu, J., Yu, B.: Estimating roof solar energy potential in the downtown area using a gpu-accelerated solar radiation model and airborne lidar data. Remote Sens. 7(12), 17212-17233 (2015)
22. Jochem, A., Höfle, B., Rutzinger, M., Pfeifer, N.: Automatic roof plane detection and analysis in airborne lidar point clouds for solar potential assessment. Sensors 9(7), 5241-5262 (2009)

23. Boz, M.B., Calvert, K., Brownson, J.R.: An automated model for rooftop PV systems assessment in ArcGIS using LIDAR. AIMS Energy 3(3), 401-420 (2015)

24. Fath, K., Stengel, J., Sprenger, W., Wilson, H.R., Schultmann, F., Kuhn, T.E.: A method for predicting the economic potential of (building-integrated) photovoltaics in urban areas based on hourly Radiance simulations. Sol. Energy 116, 357-370 (2015)

25. Santosa, T., Gomesb, N., Freirea, S., Britoc, M., Santosb, L., Tenedório, J.: Applications of solar mapping in the urban environment [J]. Appl. Geogr. 51, 48-57 (2014)

26. Redweik, P., Catita, C., Brito, M.: Solar energy potential on roofs and facades in an urban landscape. Sol. Energy 97, 332-341 (2013)

27. Tooke, T.R., Coops, N.C., Christen, A., Gurtuna, O., Prévot, A.: Integrated irradiance modelling in the urban environment based on remotely sensed data. Sol. Energy 86(10), 2923-2934 (2012)

28. Canadian Solar Industries Association (CanSIA): Roadmap 2020 - Powering Canada's Future with Solar Electricity. Canadian Solar Industries Association (CanSIA). www.cansia.ca

29. People Power Planet Partnership: Alberta Renewable Energy and Community Energy Overview. People Power Planet. www.peopl epowerplanet.ca (2018)

30. Natural Resources Canada: Photovoltaic and solar resource maps - photovoltaic potential and insolation dataset. Natural Resources Canada. www.nrcan.gc.ca (2017)

31. City of Lethbridge: About Lethbridge. City of Lethbridge. http://www.lethbridge.ca/Things-To-Do/About-Lethbridge/Pages /default.aspx. Accessed Jan 2017

32. City of Lethbridge OpenData CATALOGUE: building footprints. http://opendata.lethbridge.ca/datasets/7d32446fb333488 598268bd4bc0c830d_0. Accessed Jan 2017

33. City of Lethbridge: census results 2016. City of Lethbridge. http:// www.lethbridge.ca/City-Government/Census/Pages/Census-Resul ts-2015.aspx. Accessed Jan 2017

34. Esri Canada Ed: Canada Boundary. ArcGIS. https://www.arcgi s.com/home/item.html?id=dcbcdf86939548af81efbd2d732336db (2013). Accessed Feb 2017

35. City of Lethbridge OpenData CATALOGUE: City Boundary. http://opendata.lethbridge.ca/datasets/3d37b1a4840d4eac88bb 89a49672c2e7_1. Accessed Jan 2017

36. Esri: LAS dataset considerations. ArcGIS Help 10.1. http://resou rces.arcgis.com/en/help/main/10.1/index.html\#/LAS_dataset_ considerations/015w00000069000000/ESRI_SECTION1_104F8 5DA2EBC405E9EEBBFF61208759E/ (2013). Accessed Feb 2017

37. Esri: Creating raster DEMs and DSMs from large lidar point collections. ArcGIS for Desktop. http://desktop.arcgis.com/en/ arcmap/10.3/manage-data/las-dataset/lidar-solutions-creatingraster-dems-and-dsms-from-large-lidar-point-collections.htm. Accessed Jan 2017

38. Chaves, A., Bahill, A.: Locating sites for photovoltaic solar panels. ArcUser 13(4), 24-27 (2010)

39. Esri: How Slope works. ArcGIS Resources. http://resources.arcgi s.com/en/help/main/10.2/index.html\#/How_Slope_works/009z0 00000vz000000/ (2014). Accessed Feb 2017

40. McKenney, D.W., Pelland, S., Poissant, Y., Morris, R., Hutchinson, M., Papadopol, P., Lawrence, K., Campbell, K.: Spatial insolation models for photovoltaic energy in Canada. Sol. Energy 82(11), 1049-1061 (2008)

41. Esri: Hillshade. ArcGIS Desktop. http://pro.arcgis.com/en/proapp/tool-reference/3d-analyst/hillshade.htm. Accessed Feb 2017

42. Solar Choice: $1.5 \mathrm{~kW}$ solar PV systems, Pricing, outputs and payback. Solar Choice, https://www.solarchoice.net.au/ 
blog/1-5kw-solar-pv-systems-price-output-payback (2016). Accessed Feb 2017

43. Camargo, L.R., Zink, R., Dorner, W., Stoeglehner, G.: Spatiotemporal modeling of roof-top photovoltaic panels for improved technical potential assessment and electricity peak load offsetting at the municipal scale. Comput. Environ. Urban Syst. 52, 58-69 (2015)

44. Esri: How raster calculator works. ArcGIS for Desktop. http:// desktop.arcgis.com/en/arcmap/10.3/tools/spatial-analyst-toolbox/ how-raster-calculator-works.htm. Accessed Feb 2017

45. Esri: Area Solar Radiation. ArcGIS for Desktop. http://deskt op.arcgis.com/en/arcmap/10.3/tools/spatial-analyst-toolbox/areasolar-radiation.htm. Accessed Mar 2017

46. Ruiz-Arias, J., Tovar-Pescador, J., Pozo-Vázquez, D., Alsamamra, H.: A comparative analysis of DEM-based models to estimate the solar radiation in mountainous terrain. Int. J. Geogr. Inf. Sci. 23(8), 1049-1076 (2009)

47. Duffie, J.A., Beckman, W.A.: Solar Engineering of Thermal Processes. Wiley (2013)

48. Fu, P., Rich, P.M.: A geometric solar radiation model with applications in agriculture and forestry. Comput. Electron. Agric. 37(1), 25-35 (2002)

49. Besharat, F., Dehghan, A.A., Faghih, A.R.: Empirical models for estimating global solar radiation: a review and case study. Renew. Sustain. Energy Rev. 21, 798-821 (2013)

50. Despotovic, M., Nedic, V., Despotovic, D., Cvetanovic, S.: Review and statistical analysis of different global solar radiation sunshine models. Renew. Sustain. Energy Rev. 52, 1869-1880 (2015)

51. Wirth, H.: Recent Facts about Photovoltaics in Germany. Fraunhofer Institute for Solar Energy (ISE), Freiburg (2016)

52. Philipps, S., Warmuth, W.: Photovoltaics Report. Fraunhofer Institute for Solar Energy Systems (ISE), Freiburg (2017)

53. Schmalensee, R.: The Future of Solar Energy: An Interdisciplinary MIT Study. Energy Initiative. Massachusetts Institute of Technology, Cambridge (2015)

54. Ropp, M., Begovic, M., Rohatgi, A.: Determination of the curvature derating factor for the Georgia Tech Aquatic Center photovoltaic array. In: Photovoltaic Specialists Conference, 1997, Conference Record of the Twenty-Sixth IEEE 1997, pp. 1297-1300 (IEEE)

55. Vignola, F., Mavromatakis, F., Krumsick, J.: Performance of PV inverters. In: Proc. of the 37th ASES Annual Conference, San Diego, CA (2008)

56. Pelland, S., McKenney, D.W., Poissant, Y., Morris, R., Lawrence, K., Campbell, K., Papadopol, P.: The development of photovoltaic resource maps for Canada. In: Proc. 31st Annual Conference of the Solar Energy Society of Canada (SESCI) (2006)

57. Reich, N.H., Mueller, B., Armbruster, A., Sark, W.G., Kiefer, K., Reise, C.: Performance ratio revisited: is PR $>90 \%$ realistic? Prog. Photovoltaics Res. Appl. 20(6), 717-726 (2012)

58. Pelland, S., Poissant, Y.: An evaluation of the potential of building integrated photovoltaics in Canada. In: Proceedings of the SESCI 2006 Conference (2006)

59. MacKinnon, J., Mintz, J.: Putting the Alberta budget on a new trajectory. University of Calgary, the School of Public Policy Publications (2017)

60. Statistics Canada: Consumer Price Index, by province (Alberta). Statistics Canada. https://www.statcan.gc.ca/tables-tableaux/sumsom/101/cst01/econ09j-eng.htm (2018). Accessed Mar 2018

61. Government of Alberta: Electricity price protection. Alberta. https ://www.alberta.ca/electricity-price-protection.aspx. Accessed Mar 2018

62. Alberta Electric System Operator (aeso): Transmission costs. Alberta Electric System Operator. https://www.aeso.ca/grid/trans mission-costs/ (2016). Accessed Mar 2018

63. Kuby Renewable Energy Ltd: The cost of solar panels. Kuby Renewable Energy Ltd.https://kubyenergy.ca/blog/the-cost-ofsolar-panels. Accessed Mar 2018

64. Alberta Government: Rebates to help Albertans tap solar resources. Alberta. https://www.alberta.ca/relea se.cfm?xID=463610A3269CE-0D2C-C140-6E391B3112A5666 4 (2017). Accessed Mar 2018

65. Poissant, Y., Baldus-Jeursen, C., CanmetENERGY, Natural Resources Canada, Bateman, P., Canadian Solar Industries Association: National Survey Report of PV Power Applications in Canada-2016. International Energy Agency (2017)

66. Thevenard, D., Pelland, S.: Estimating the uncertainty in longterm photovoltaic yield predictions. Sol. Energy 91, 432-445 (2013)

67. Environment Lethbridge: Lethbridge State of the Environment 2017. Environment Lethbridge Council. www.environmentleth bridge.ca (2017)

68. Alberta Government: Climate Leadership Plan Progress Report 2016-17. Alberta Government (2017)

Publisher's Note Springer Nature remains neutral with regard to jurisdictional claims in published maps and institutional affiliations. 